\title{
HOX gene cluster (de)regulation in brain: from neurodevelopment to
} malignant glial tumours

5

6

7

8 9

Authors: Céline S. Gonçalves ${ }^{1,2, a}$, Elisa Le Boiteux ${ }^{3, \text { a }}$, Philippe Arnaud ${ }^{3, \mathrm{~b}}$, Bruno M. Costa ${ }^{1,2, \mathrm{~b}}$

${ }^{1}$ Life and Health Sciences Research Institute, School of Medicine, University of Minho, Braga, Portugal;

${ }^{2}$ ICVS/3B's-PT Government Associate Laboratory, Braga/Guimarães, Braga, Portugal;

${ }^{3} \mathrm{GReD}$, Université Clermont Auvergne, CNRS, INSERM, Clermont-Ferrand, France.

a - equally contributing

b - co-senior authors

Céline S. Gonçalves ORCID: 0000-0002-3713-119X

Philippe Arnaud ORCID: 0000-0002-7937-8764

Bruno M. Costa ORCID: 0000-0003-4861-7432

Corresponding Author: Bruno M. Costa, Life and Health Sciences Research Institute (ICVS), School of Medicine, University of Minho, Campus de Gualtar, 4710-057 Braga, Portugal. Email: bfmcosta@med.uminho.pt; Phone: (+351)253604837; Fax: (+351)253604831 


\section{Abstract:}

HOX genes encode a family of evolutionarily conserved homeodomain transcription factors that are crucial both during development and adult life. In humans, 39 HOX genes are arranged in four clusters (HOXA, B, C, and D) in chromosomes 7, 17, 12 and 2, respectively. During embryonic development, particular epigenetic states accompany their expression along the anterior-posterior body axis. This tightly regulated temporal-spatial expression pattern reflects their relative chromosomal localization, and is critical for normal embryonic brain development, when HOX genes are mainly expressed in the hindbrain and mostly absent in the forebrain region. Epigenetic marks, mostly polycombassociated, are dynamically regulated at HOX loci and regulatory regions to ensure the finely tuned HOX activation and repression, highlighting a crucial epigenetic plasticity necessary for homeostatic development. HOX genes are essentially absent in healthy adult brain, whereas they are detected in malignant brain tumours, namely gliomas, where HOX genes display critical roles by regulating several hallmarks of cancer. Here, we review the major mechanisms involved in HOX genes (de)regulation in the brain, from embryonic to adult stages, in physiological and oncologic conditions. We focus particularly on the emerging causes of HOX gene deregulation in glioma, as well as on their functional and clinical implications.

Keywords: glioma; epigenetics; transcriptional regulation; neurodevelopment; homeobox

Abbreviations: 3C: chromosome conformation capture; 3D: 3-dimensional; 4C-seq: circularized chromosome conformation capture with deep sequencing; $5 \mathrm{C}$ : chromosome conformation capture carbon copy; AQB: AC1Q3QWB drug; CAM: chicken chorioallantoic membrane; CGGA: Chinese Glioma Genome Atlas; ChIP: chromatin immunoprecipitation; CHROMO: chromatin organization modifier; CNS: central nervous system; CNV: copy number variations; COMPASS: complex proteins associated with Set1; DNA: deoxyribonucleic acid; ESCs: embryonic stem cells; GBM: glioblastoma; G-CIMP: glioma $\mathrm{CpG}$ island methylator phenotype; GSCs: GBM stem cells; H2AK119ub: ubiquitination of H2AK119 residues; H3K27ac: histone H3 lysine 27 acetylation; H3K27me3: histone H3 lysine 27 trimethylation; H3K4me3: histone H3 lysine 4 trimethylation; Hi-C: chromosome capture followed by high-throughput sequencing; HOX: homeobox; HUVEC: human umbilical vein endothelial cells; LGG: low-grade gliomas; lncRNA: long non-coding RNA; miRNAs: micro RNA; mRNA: messenger RNA; OS: overall survival; PARs: promoter-associated RNAs; PcG: polycomb group; PCR: polymerase chain reaction; PDX: patient-derived xenograft; PRE: polycomb responsive element; RA: retinoic acid; RNA: ribonucleic acid; SINE: short interspersed nuclear elements; TAD: topological associating domain; TCGA: The Cancer Genome Atlas; TMZ: 
1 temozolomide; TrxG: trithorax-group proteins; TSS: transcription start sites; WHO: World Health 2 Organization

3 


\section{Introduction}

Genetic mutations in the fruit fly Drosophila melanogaster that resulted in homeotic transformations of one body segment to another (e.g., antennae growing at the posterior part instead of at the head of the fly) led to the identification of master transcriptional regulators named homeobox genes [1-5]. These genes are characterized by a consensus DNA sequence of 183 base pairs, the so-called homeobox, that encodes the homeodomain, a 61 -amino acid peptide motif with a distinctive helixloop-helix-turn-helix structure [6]. This homeodomain serves, among other functions, as a DNA binding domain that preferentially recognizes a specific TA-rich core DNA sequence, such as TAAT or TTAT [7-10]. Homeobox genes are of paramount importance for the developmental and postdevelopmental regulation of morphogenesis, patterning and differentiation, independently of the organ, limb or tissue where they are expressed [11-19].

HOX genes represent the main subset of the homeobox family. They display evolutionarily conserved transcription factor functions common to all bilaterian animals [20], and are considered crucial for the establishment of segmental identity along the anterior-posterior body axis of vertebrates. HOX proteins also have non-transcriptional activities and are implicated in regulating various processes, such as DNA replication and repair, mRNA translation, and protein degradation (reviewed by Rezsohazy et al. [21]). Structurally, they are divided into two exons and one intron, being the homeobox sequence present in the second exon (Fig. 1A). In D. melanogaster, eight collinear HOX genes, split into two clusters (the antennapedia and bithorax complexes), are responsible for segmental patterning. In amniotes, there are 39 HOX genes distributed into four clusters (HOXA, HOXB, HOXC, and HOXD) according to their chromosomal localization (7p15, 17q21.2, 12q13, and 2q31, respectively, in humans) [22]. Each cluster is divided into 13 paralogue groups (HOX1 at the 3 ' end to HOX13 at the 5' end of each cluster), with 9 to 11 genes assigned to each cluster, based on their sequence homology and position within the cluster (Fig. 1B). It is thought that these four clusters originated during vertebrate evolution due to two rounds of whole genome duplication that resulted in paralogue clusters with partial redundant functions $[20,23,24]$. The temporal-spatial collinear expression of HOX genes during embryogenesis $[25,23]$ is one of the most organized and captivating mechanisms of gene regulation, in which the expression pattern of each paralogue group directly mirrors their collinear chromosomal organization. The first paralogues (HOX1 and HOX2) are the first to be expressed (shortly after the establishment of the primitive streak), followed by the other paralogues (from the 3 ' end to the 5' end in each cluster) in a time/developmental stage-dependent manner. In addition to their temporally regulated expression, they are gradually expressed from more anterior regions to more posterior regions of the embryo. This spatial collinearity (i.e., the relation between the relative chromosomal position of a HOX gene and its spatial expression in the body) was 
1 first described in D. melanogaster [4]. Since then, it has been observed throughout the animal

2 kingdom [26]. Nonetheless, temporal collinearity is reserved to bilaterians with intact chromosomal

3 organization of HOX in clusters [27,28]. Unsurprisingly, at least 15 genetic disorders were associated

4 with germline mutations in 10 out of 39 HOX genes in humans (as reviewed in Quinonez, Innis [29]).

5 In mouse, loss-of-function mutations of 26 out of 28 tested Hox genes resulted in a particular

6 phenotype/defect in the animal, which mirrors those observed in humans and may thus help clinicians

7 to better predict the effects of alterations in specific HOX genes in patients [29].

8 This review will critically summarize the major molecular mechanisms of transcriptional regulation

9 of HOX genes in the healthy brain, with a special focus on their dynamic epigenetic landscapes during critical stages of neuro-development. In addition, it will discuss the most critical molecular alterations and functional roles of HOX genes in brain tumours, as well as their recently highlighted clinical relevance in patients.

\section{General principles of HOX regulation}

The collinear activation, in time and space, of HOX genes during vertebrate development relies on a multi-scale regulation that involves the cis-regulatory landscape, the three-dimensional (3D) chromatin configuration, the histone modification pattern and RNA-based regulation [27].

- Proximal and remote cis-regulatory regions

Early studies in transgenic mice showed that some individual Hox genes inserted at ectopic positions in the genome can recapitulate their endogenous expression pattern, indicating that the necessary regulatory sequences are in their vicinity [30,31]. Accordingly, multiple proximal cis-regulatory sequences that can influence transcription of neighbouring genes were identified within Hox clusters [32-34]. For instance, two retinoic acid (RA) response elements embedded in the Hoxb cluster control expression of Hoxb5 to Hoxb9 in the developing neural tube [35]. Such proximal regulatory sequences provide a frame for the evolutionary conserved temporal collinear activation of HOX genes. However, novel HOX-associated patterning functions, which often use the collinear property of only a subset of genes from the same cluster, emerged in vertebrate lineages. These novel functions often rely on cis-regulatory sequences located outside the HOX cluster. For instance the development of both proximal and distal limb segments, in the limb buds, relies on two subsequent waves of Hoxd genes transcription, controlled by distinct remote $c i s$-regulatory regions located on each side of the gene cluster [36-38]. A similar long-range regulation is also documented at the other HOX clusters to control the coordinated activation of HOX genes in specific developmental stages and tissues [4143]. These observations revealed the importance of the remote transcriptional control to the HOX- 
mediated patterning of the developing vertebrate embryo. In addition, as the distant enhancers and HOX promoters must physically interact, the $3 \mathrm{D}$ chromatin conformation has to be taken into account to understand HOX regulation. Accordingly, a significant advance in our understanding of HOX control came with the development of molecular tools to assess the 3D genome organization at highresolution.

- A 3D chromatin conformation-based regulation

The development of the Chromosome Conformation Capture (3C) methodology and its derivatives (circularized chromosome conformation capture with deep sequencing, 4C-seq; chromosome conformation capture carbon copy, 5C; and chromosome capture followed by high-throughput sequencing, Hi-C) [44] allowed the analysis of the relationship between genome architecture and gene expression control over time. Specifically, Hi-C approaches showed that chromosomes are divided into mega base-scale regions, called Topological associating domains (TADs) in which chromatin interactions are highly favoured $[45,46]$. These domains are relatively stable in the different cell types, and are proposed to be structural features of the genome [45]. Strikingly, both HOXA and HOXD clusters lie at the boundary between two TADs [45]. This topological organization might separate these compact gene clusters in two independent functional units that will specify contacts between remote enhancers and their cognate HOX target genes during development (Fig. 2). This scheme explains the bi-modal regulation of the Hoxd cluster during limb development. Longrange interactions between the 3' Hoxd genes and enhancers located in the telomeric gene desert occur within the 3' (telomeric) TAD. Conversely, 5' genes segregate in the 5' (centromeric) TAD where they contact enhancers in the centromeric gene desert. Interestingly, a subset of contacts between Hox promoters and their distal enhancers occur by default within the TAD, regardless of the enhancer activity and their expression status $[39,41]$. In parallel to the enhancer-promoter contacts established concomitantly with gene activation $[48,49]$, this pre-established configuration at a subset of genes might prime them for rapid induction $[32,50]$.

The molecular bases of TAD ontogeny at HOX cluster are not fully understood. A critical factor is the chromatin barrier insulator CTCF (CCCTC-binding factor) that is often located at TAD boundaries [45]. Specifically, deletion of CTCF binding sites within the Hoxa cluster can reposition the TAD boundary and lead to misregulation of Hox genes expression [51,52]. However, other yet to be identified actors might contribute to TAD boundary positioning [53]. These include the structural protein cohesin that promotes DNA loop formation between distant regions [54], as well as genomic features, such as the presence of short interspersed nuclear elements (SINE) [45]. Tissue-specific transcription factors also could influence TAD boundary position. This hypothesis is supported by 
the observation that this position can vary in a tissue-specific manner at the HOXA and HOXD clusters (reviewed in [32]), with reallocation of some genes from one TAD to the other. Therefore, there could be an interplay between intra-cluster TAD boundaries and tissue-specific transcriptional machinery [32].

Unlike HOXA and HOXD, the HOXB and HOXC clusters are not associated with a TAD boundary [45], suggesting that TADs are not required for long-range regulations within these clusters. Their genomic organization might create a physical separation between the 3' and 5' parts of each cluster. Indeed, due to its remote localization, $H O X B 13$ is isolated from $H O X B 1-H O X B 9$, while the HOXC cluster does not contain paralogues for the groups 1-3 (Fig. 1B).

- HOX genes are bona-fide polycomb targets

HOX gene activation is associated with dynamic changes in their chromatin signature. Hence, expression patterns induced by productive enhancer-promoter contacts are maintained and faithfully transmitted to daughter cells. Besides the gain of the activating H3K27ac (acetylation of histone H3 lysine 27) mark within enhancers [55], the most drastic changes affect the distribution of the repressive $\mathrm{H} 3 \mathrm{~K} 27 \mathrm{me} 3$ and the permissive $\mathrm{H} 3 \mathrm{~K} 4 \mathrm{me} 3$ marks within HOX clusters.

In embryonic stem cells (ESCs), which do not express HOX genes, whole HOX clusters are fully decorated by H3K27me3, while at their promoter area this mark co-exists with H3K4me3, constituting the so-called bivalent chromatin [56,57] (Fig. 3A). It has been suggested that bivalent chromatin domains repress transcription of genes through H3K27me3, while keeping them 'poised' for alternative fates, through resolution into either $\mathrm{H} 3 \mathrm{~K} 4 \mathrm{me} 3$ or $\mathrm{H} 3 \mathrm{~K} 27 \mathrm{me} 3$, upon stem cell differentiation [56]. In the developing embryo, collinear activation of HOX genes is accompanied by a progressive loss of $\mathrm{H} 3 \mathrm{~K} 27 \mathrm{me} 3$ associated with H3K4me3 gain. Consequently, H3K27me3- and H3K4me3-marked domains demarcate repressed and active HOX genes, respectively, along the cluster (Fig. 3B). In differentiated cells and tissues where all HOX genes are repressed, such as the forebrain, H3K27me3 coats the whole clusters $[58,59,57]$ (Fig. 3C). This observation highlights the importance of the polycomb $(\mathrm{PcG})$ and trithorax $(\mathrm{TrxG})$ groups of proteins that regulate $\mathrm{H} 3 \mathrm{~K} 27 \mathrm{me} 3$ and $\mathrm{H} 3 \mathrm{~K} 4 \mathrm{me} 3$ deposition, respectively, in the epigenetic regulation of HOX genes.

PcG-mediated silencing relies on two complexes that act sequentially: Polycomb Repressive complex 1 and 2 (PRC1 and PRC2). In the canonical model, PRC2 first deposits H3K27me3 at the targeted chromatin. $\mathrm{H} 3 \mathrm{~K} 27 \mathrm{me} 3$ then recruits PRC1 that induces a compacted chromatin state mainly through ubiquitination of H2AK119 residues (H2AK119ub). This two-step model is supported by the finding that while both complexes are required for proper HOX gene silencing [60,58,61], PRC1 deficiency 
does not affect the PRC2-mediated H3K27me3 pattern [58]. Unlike in Drosophila, no polycomb responsive element (PRE) has been formally described in vertebrates, questioning the mechanism for PRC targeting at specific loci. The observation that PRC2 components can associate with long noncoding RNAs (lncRNA) and promoter-associated RNAs (PARs) suggests the implication of RNA transcripts in this process [62-64]. For instance, the lncRNA HOTAIR, which is produced in the 5, part of the HOXC cluster, recruits PRC2 and acts in trans to silence the genes located in the 5' part of the HOXD cluster in cultured cells $[63,65]$. Similarly, it has been suggested that Hoxa adjacent lncRNA 1 (Harl1), a lncRNA located approximatively $50 \mathrm{~Kb}$ downstream of the HOXA cluster, represses this cluster in mouse ESCs by recruiting PRC2 to Hoxa promoters [66]. However, functional studies in animals indicate that Harll is dispensable for normal development [67,68], and brought conflicting results on Hotair [69-71], questioning the role of lncRNAs in the regulation of HOX clusters in vivo. It has also been proposed that PRC2 recruitment could be responsive to permissive chromatin signatures at promoters [72]. In agreement, studies in mammalian cells and tissues showed that $\mathrm{PRC} 2$ is recruited by default at transcriptionally inactive $\mathrm{CpG}$ islands/promoters $[73,74]$.

TrxG proteins are the second main epigenetic regulator of HOX clusters. Specifically, deposition of H3K4me3 at HOX clusters in mammals relies on the COMPASS-like complex that contains MLL1 and 2, the homologues of Drosophila Trx [75]. Interestingly, this complex also contains the H3K27me3-demethylase KDM6A that removes H3K27me3 at HOX loci [76-78]. This suggests that H3K4me3 deposition and H3K27me3 removal are coupled at HOX promoters. Like for PRC2, it has been suggested that lncRNAs promote recruitment of the TrxG/MLL complex. For instance, HOTTIP, located at the 5' tip of the HOXA locus, recruits in cis the WDR5/MLL proteins and promotes H3K4me3 deposition [79]. Alternatively, as observed for other COMPASS-like complexes [80], TrxG/MLL complexes could be recruited at promoters through association with the transcriptional machinery.

- Active and repressed HOX genes are within distinct nuclear compartments in the nucleus

Altogether, a model emerges whereby $\mathrm{H} 3 \mathrm{~K} 27 \mathrm{me} 3$ is deposited by default at transcriptionally inactive HOX genes, a process that can be promoted by lncRNA activity. Upon enhancer-induced activation, the transcriptional machinery would bring TrxG/MLL/KDM6A complexes to promoters to sustain HOX gene transcriptional activity by inducing H3K4me3 deposition and H3K27me3 removal. Interestingly, the dynamics of $\mathrm{H} 3 \mathrm{~K} 27 \mathrm{me} 3 / \mathrm{H} 3 \mathrm{~K} 4 \mathrm{me} 3$ distribution along the different $\mathrm{HOX}$ clusters impacts their 3D architecture. Indeed, $4 \mathrm{C}$ approaches showed the segregation of active and repressed HOX genes within distinct nuclear compartments [55,59]. Specifically, H3K27me3-marked HOX 
loci cluster together within inactive nuclear compartments, denoted polycomb bodies, where they can contact, although at a lower frequency, other polycomb targets through intra- and inter-chromosomal interactions [+ Pirotta \& Li, 81,82]. Upon induction, HOX genes switch to more discrete H3K4me3associated compartments, thus modifying the cluster 3D organization $[55,59]$. This spatial separation between the silent and expressed parts of HOX clusters might facilitate their finely tuned regulation.

- $\quad$ miRNA and post-transcriptional regulation

In addition to transcriptional regulation, HOX expression is also controlled at the post-transcriptional level by the mean of several processes, including polycistronic transcription, RNA processing or sequence-specific transcriptional control. These issues have been recently extensively reviewed [Casaca et al., 2018]. Among those, one important mechanism is regulation via microRNA (miRNA) repression. These short RNA species negatively regulate gene expression by binding target mRNA in a sequence-specific manner, further leading to degradation via the RNA-induced silencing complex (reviewed in Bartel, 2018). Several highly conserved miRNA families are embedded within HOX clusters, including for instance the miR-10, miR-615 and miR-196 families. Interestingly, among the predicted targets of these HOX-embedded miRNAs, many are protein-coding HOX mRNAs [Yekta et al., 2008]. To which extent these miRNAs indeed contribute to control and coordinate HOX output remain to be fully determined. Nonetheless, functional studies have highlighted that miR-196 and miR-10 do contribute to HOX mRNA regulation in vertebrates [Mandsfiled and McGlinn, 2012; Casaca, 2018]. This is best illustrated by miR-196 that acts by delimiting Hoxb8 activity in developing hind limb and neural tissue [Hornstein , 2005; Asli and Kessel, 2010].

\section{Roles of HOX genes in the developing brain}

Most HOX genes are expressed in the developing vertebrate central nervous system (CNS) where they have critical functions. They first play a central role in cell fate determination within hindbrain and spinal cord segments, further contributing to the establishment of functional neuronal networks [86; 98]. These structures are indeed key coordination centres of the CNS that, via dedicated neural assemblies, regulate complex physiological processes, including breathing, locomotion, heartbeat, and different sensory systems [107].

Following the onset of neural induction, the early vertebrate hindbrain is transiently segmented in seven or eight cellular compartments, depending on the species, called rhombomeres ( $r 1$ to r8) (Fig. 1B). While no physical barrier exists between them, cells of each rhombomere remain well segregated and do not mix with those of the other rhombomeres $[83,84]$. Each of these segments constitutes an independent lineage-restricted unit that creates regional diversity along the anterior-posterior axis of 
the developing hindbrain, thus acting as a template for the future adult brainstem structure and function. Each rhombomere is the source of distinctive neural progenitors that ultimately generate rhombomere-specific populations of neurons [85]. For instance, among motor neurons, trigeminal neurons develop in $\mathrm{r} 2 / \mathrm{r} 3$, while facial and vagal neurons form in $\mathrm{r} 4$ and $\mathrm{r} 7 / \mathrm{r} 8$, respectively. Although such a clear segmentation is not present in the spinal cord, neuronal regional diversity is also observed along the anterior-posterior axis. Specifically, spinal motor neurons are organized into longitudinal columns along the four main spinal cord units: cervical, thoracic, lumbar and sacral [86]. For instance, phrenic motor neurons are generated at the anterior cervical level, while preganglionic and hypaxial neurons form at the thoracic level (Fig. 1B).

Strikingly, specific combinations of Hox gene expression and/or expression levels define the regional identity in hindbrain and spinal cord. Specifically, Hox1-Hox5 paralogue group genes display rhombomere-specific nested expression patterns in hindbrain. Similarly, Hox4-Hox11 genes are expressed in a nested fashion along the anterior-posterior spinal cord axis [87,88,86,89] (Fig. 1B). Disturbance of these patterns in the mouse and other vertebrate models have revealed that HOX genes play a key role in the segmentation and specification of several rhombomeres in hindbrain, and in the maintenance of columnar identity in spinal cord $[90-93,86]$.

The HOX combinatorial code in hindbrain and spinal cord is also involved in key steps of neural development by acting as a determinant to control the formation of distinct neuronal subtypes within the different segments. Specifically, studies conducted on motor neuron specification highlighted the importance of HOX transcription factors in regulating the diversity and identity of motor neuron pools in spinal cord, and in establishing the pattern and specificity of limb muscle innervation $[94,90,95,92,86,96]$. In addition, studies conducted in Hox conditional mouse mutants support a role for Hox genes in later stages of CNS development to generate neural circuit assemblies. For instance, the formation of respiratory, somatosensory and auditory circuits is perturbed in the absence of specific Hox genes [97-99].

Therefore, neuronal subtype specification and connectivity in hindbrain and spinal cord rely on HOXspecific expression patterns and the associated regionalization along the anterior-posterior axis. These expression patterns are set up sequentially during two phases of regulation in progenitors and postmitotic neurons, respectively. They involve a complex interplay between morphogen signals, crossregulatory interactions between Hox genes, and polycomb-associated epigenetic modifications. First, in the neural tube, opposite gradients of RA and Fibroblast growth factor (FGF) signalling act in concert to establish the initial Hox expression pattern in the early CNS [100,18]. RA primarily promotes the expression of the Hox 1-5 paralogue group of genes through activation and direct binding 
of RA receptors (RARs) [101]. In spinal cord, FGF establishes the Hox4-Hox10 gene expression patterns through the induction and subsequent binding of the homeodomain protein factors CDX $[102,103]$. Studies in differentiating mouse neural progenitors showed that binding of RARs and CDX to their cognate Hox target genes and their subsequent activation are associated with the rapid removal of the repressive $\mathrm{H} 3 \mathrm{~K} 27 \mathrm{me} 3$ mark [104]. This chromatin remodelling provides a template to transmit these initial gene expression patterns to early post-mitotic neurons where they will be refined and segmentally restricted. Although neural progenitors display a nested pattern of Hox expression, clear Hox posterior boundaries will be indeed established at the time of differentiation and often maintained up to late foetal stages in restricted neuronal subpopulations. This second regulatory phase relies on direct self- and cross-regulatory interactions between HOX transcriptions factors and Hox genes, associated with the combined action of other transcription factors $[105,106]$. For instance, a complex interplay between the KROX20 transcription factor and the Hox 1 and Hox 2 paralogue groups ensures that $H o x b 1$ expression is restricted to $\mathrm{r} 4$ in the vertebrate hindbrain, where it will be then maintained through an auto-regulatory loop [107,108]. EZH2, the enzymatic component of PRC2, is required to maintain Hox expression patterns in the segmented hindbrain. Accordingly, its neural-specific depletion in the mouse leads to migration and connectivity defects of pre-cerebellar pontine neurons [109]. In the spinal cord, PRC2-mediated H3K27me3 pattern at Hox loci is determined during the progenitor phase. However, Hox gene expression pattern is refined and maintained in post-mitotic cells through a mechanism that seems to depend on PRC1, the other PRC complex. Specifically, depletion of the PRC1 component BMI-1 affects Hoxc 9 expression and the spinal cord columnar identity [110].

After neurulation, HOX expression patterns are maintained up to late foetal/early post-natal stages in restricted neuronal subpopulation of the hindbrain, and in restricted domains of the spinal cord [95,98,99, Gofflot and Lizen, 2018]. A handful of studies further report that HOX expression may persist post-natally and in the adult brain. For instance, RT-PCR analyses in human adult brain extract highlighted the expression of the 3' HOX genes (HOX1-HOX7 paralogues) [12]. A more systematic analysis conducted in the adult mouse brain evidenced that the expression of genes belonging to Hox2-Hox8 paraloguegroups is maintained in the hindbrain derivatives. The same analysis also support that some Hox transcripts are neo-expressed in specific brain regions at adulthood [Hutlet et al., 2014]. These observations suggest that HOX transcripts could be functionally required in the brain after birth, stressing the need to formally assess their function at adulthood. Indeed, several lines of evidence mainly based on functional in vivo data obtained for the Hoxa 2 and Hoxa 5 loci suggest a role in synapse formation and maturation [reviewed in Gofflot and Lizen, 2018]. Unlike in hindbrain and spinal cord, HOX genes are not expressed in the developing forebrain, the most anterior part of 
the developing CNS, and also in adult brain [111]. This repression is mediated by H3K27me3 [59], and is critical for brain expansion. This evolutionary conserved feature of the CNS leads to a more prominent anterior region (brain) compared with the posterior ones. A study conducted in Drosophila and the mouse revealed that brain expansion is severely reduced following Hox ectopic expression, or loss of PcG function [112]. Surprisingly, mutation of the $A b d-B$ HOX gene rescues the reduced brain proliferation observed in PRC2 mutants in Drosophila. This intriguing observation, which has not yet been assessed in vertebrate brain, suggests that in the developing Drosophila brain, one of the primary roles of PRC2 is to repress Hox genes [113]. From this analysis, it emerges a picture whereby HOX genes repress the neural stem cell proliferation programme in the more posterior parts. PcGmediated repression of HOX genes prevent this anti-proliferative action in the forebrain, thus promoting brain expansion [113]. Altogether, this observation stresses the importance of maintaining HOX genes repressed in forebrain.

\section{HOX deregulation in brain gliomas}

HOX genes may present tumour suppressive or oncogenic functions, and their expression is frequently altered in cancer, including leukaemia [114-118], breast [119-121], brain [122-127], lung [128,129], colon [130], cervix [131], bladder [132,133], and kidney cancers [134]. In the context of this review, we will focus on brain tumours, specifically high-grade gliomas.

\subsection{Malignant primary brain tumours}

Malignant primary brain tumours represent approximately $32 \%$ of all brain tumours and affect more than 250000 individuals each year worldwide (1 $7^{\text {th }}$ most common cancer type) [135]. Despite their relatively low incidence compared with other primary cancers (e.g., lung, breast, prostate and colorectal cancers) and metastatic brain tumours, they constitute a major source of morbidity and mortality. They are the $12^{\text {th }}$ most deadly cancer worldwide (almost 190000 estimated deaths per year) [135], and rank first in average of years of life lost among all tumour types [136].

Gliomas represent the majority of all malignant brain tumours (81\%).

Until 2016, gliomas were traditionally classified based on histologic features as astrocytic, oligodendroglial, oligoastrocytic (mixed), or ependymal tumours, as described in the 2007 World Health Organization (WHO) classification guidelines [139]. In this classification, tumours were named after the normal cells from which they resembled. However, this classification methodology was prone to considerable inter-observer variability, particularly in the context of diffusely infiltrating gliomas (e.g., differences in the classification of astrocytoma vs. oligodendroglioma vs. oligoastrocytoma) [140-142]. Moreover, advances in (epi)genetics and transcriptomic analyses have 
shed light on the biological and clinical variability observed within each histologically-defined glioma entity $[143,142]$. These observations suggested that some of the molecular alterations underlying this variability might in fact be used as biomarkers for more accurate glioma classification [143], which contributed to the 2016 revision of the guidelines [141]. For example, according to the most recent WHO classification of CNS tumours, gliomas can be isocitrate dehydrogenase (IDH)wildtype or IDH-mutant [142]. Gliomas are also stratified according to their malignancy grade, from benign grade I to highly-malignant grade IV. Glioblastoma (GBM) is the most common and malignant form of glioma [137], being almost universally fatal with very low 2- and 5-year survival rates [138]. IDH-wildtype GBMs are the most common (90\%), occur mainly in elderly patients (median age at diagnosis: 62 years), are localized in the supratentorial region, and correspond to primary GBM that develop de novo (i.e., with a short clinical history of less than 3 months before diagnosis, and without a pre-existing lower-grade precursor lesion) $[143,142]$. They are associated with copy number gains on chromosome 7 (where the HOXA cluster is located), chromosome 10 monosomy, EGFR amplification, and mutations in PTEN, TERT, CDKN2A and CDKN2B genes. $T E R T$ promoter mutation is mutually exclusive with $A T R X$ mutation, which are common in IDHmutant GBM [142]. IDH-mutant GBMs typically occur in younger adults (median age at diagnosis: 44 years), are preferentially localized in the frontal lobe, and include most of secondary GBMs (i.e., GBMs that develop from a pre-existing diffuse or anaplastic astrocytoma) $[142,143]$. These tumours are characterized by copy number gains on chromosome 7 , loss of heterozygosity of the $17 \mathrm{p}$ arm, TP53 and ATRX mutations, and the glioma CpG island methylator phenotype (G-CIMP) [142,143].

\subsection{Aberrant HOX gene expression in glioma}

Abdel-Fattah et al. [125] were the first to report the aberrant overexpression of 9 of the 39 HOX genes (HOXA6, A7, A9, A13, B13, D4, D9, D10, and D13) in gliomas compared with normal human astrocytes and temporal lobe cells (these may include astrocytes, microglia, and neurons; summarized in Table 1). In 2008, Murat et al. [124] described the overexpression of several HOX genes (HOXA2, $A 3, A 5, A 7, A 9, A 10, C 6, D 4, D 8$, and $D 10)$ in tumour samples compared with non-neoplastic brain samples from patients with GBM. In 2009, Buccoliero et al. [144] analysed the expression of HOXD genes in 14 paediatric grade I gliomas and 6 non-neoplastic human brain tissues, and described that $H O X D 1$ and $H O X D 12$ were overexpressed in grade I gliomas compared to non-neoplastic tissues, while $H O X D 3, D 8, D 9$, and $D 10$ presented lower expression in grade I glioma (the last three were exceptionally expressed in non-neoplastic tissues). On the other hand, HOXD4, D11, and D13 were not expressed in grade I glioma. Sun et al. [145] reported later that HOXD10 was expressed in GBM. In 2010, Costa et al. [122] showed widespread activation of HOX genes (HOXA1, A2, A3, A4, A5, $A 7, A 9, A 10, B 7$, and $C 6$ ) in a subset of GBM patients compared with less malignant gliomas or 
normal brain tissues. Duan et al. [146] later corroborated these findings by describing that HOXA9, A11, and A13 proteins, and $H O X A 9, A 10, A 11$, and $A 13$ mRNA levels were strongly upregulated in GBM compared with grade II/III gliomas. However, HOXA11 expression was significantly downregulated in recurrent GBMs compared with primary GBMs [147]. Several other studies also reported the overexpression of specific HOX genes in GBM compared with non-neoplastic brain samples: HOXA1 [148], HOXA9 [150], HOXA13 [146], HOXB3 [151], HOXB7 [152], HOXB9 [153], HOXC6 [154], HOXC9 [155], HOXC10 [156,157], HOXD4 [158], and HOXD9 [126]. Among these genes, HOXA1, HOXA9, HOXA13, HOXB9, and HOXC10 were expressed in a grade-dependent manner [148,150,146,153,156]. HOXB1 and $H O X D 10$ expression levels were shown to be lower in glioma than in non-neoplastic samples $[159,160]$, and $H O X B 1$ particularly low in GBM compared to grade I and II gliomas. Moreover, Gaspar et al. [123] found that $H O X A 2, A 5, A 7$, and $A 9$ were overexpressed in short-term ( $<1$ year) paediatric GBM survivors compared with long-term survivors. Gallo et al. [161] identified a specific gene signature of patient-derived GBM stem cells (GSCs), compared with normal human foetal neural stem cells and non-neoplastic brain cortical tissues, which included 24 of the 39 HOX genes. In agreement, Li et al. [162] reported that CD133 expression, a marker of GBM stem cells, correlates with HOXA5, A7, A10, C4, and C6 expression in GBM.

In summary, different studies reported that the expression of several HOX genes is consistently altered in glioma. The few discrepancies among studies, in which a particular HOX gene was described to be up- and down-regulated, might be explained by: i) the different methods used to evaluate gene/protein expression; ii) the different processing and origin of patients' samples; iii) the use of cell lines in some studies and tumour samples in others; and iv) the different types of samples used to define the "non-tumour" condition. Some of these limitations could be mitigated by using larger cohorts of equally processed and normalized samples (e.g. [163,164], $\mathrm{n}>500$ glioma samples), and by defining standard methodologies for assessing gene expression alterations in these tumours.

\subsection{HOX functional roles in GBM}

Considering the aberrant expression of HOX genes in GBM, it is reasonable to hypothesize that they might be functionally relevant for the pathophysiology of these tumours. Various studies based on genetic manipulations of these genes, employing silencing or overexpressing approaches, reported that 18 of the $39 \mathrm{HOX}$ genes, have important functional roles in glioma, including HOXA5, A6, A7, $A 9$, A10, $A 11, A 13, B 1, B 3, B 7, B 9, B 13, C 6, C 9, C 10, D 4, D 9$, and D10. Most of the described roles are associated with oncogenic functions, although HOXA11, HOXB1, and HOXD10 displaying tumour suppressive functions in GBM (summarized in Fig. 4).

$\underline{\text { HOX genes act mostly as oncogenes in glioma: }}$ 
1 The genetic manipulation of $H O X A 5, A 9, A 10, A 13, B 3, B 7, B 9, C 6, C 9, C 10$, and $D 9$ showed that 2 their expression increases the viability of GBM cell lines $3[151,154,152,149,146,153,161,157,156,150,126,165,122]$, and five of them (HOXA9, A13, C6, C10,

4 and $D 9$ ) also reduce cell death $[122,146,156,150,126,151]$. $H O X A 7, A 9, B 7, B 9, C 9$, and $C 10$ also increased GBM cell lines migration capacity [166,152,153,157,156,150,165], while HOXA6, A13, $B 3$, and $B 13$ promoted increased invasion $[166,152,153,157,167,156,150,151,165,146]$. Interestingly, $\mathrm{HOXC6}, \mathrm{Cl} 10$, and $\mathrm{D} 9$ also increased GBM cell lines colony formation capacity [157,156,126,154], and HOXA13, C6, and D9 prevented cell cycle arrest [146,126,154].

Additionally, HOXA9 and HOXB9 increased GBM stem cell capacity and increased expression of stem cell markers (e.g., NESTIN) in vitro [153,150]. Similarly, HOXD9 was highly expressed in the "side population" of GBM cells, a population of cells identified by flow cytometry and associated with cancer stem cell features, and in GSCs compared with normal astrocytes and neural stem/progenitor cells [126]. Interestingly, $\mathrm{HOXC} 9$ was one of the 16 genes upregulated in $\mathrm{CD} 133^{+}$, a glioma stem cell marker, but not in CD133- GBM cell lines, compared in both cases with nonneoplastic cells. Moreover, in this 16-gene list, HOXC9 and E2F2 were the only genes associated with increased glioma malignancy [155].

In another in vitro study, $\mathrm{HOXC9}$ was shown to decrease Beclin1-mediated autophagy through inhibition of DAPK1 (death-associated protein kinase 1) [165]. Moreover, it has been reported that HOXA9 and HOXC10 increase tumour angiogenesis in vitro and in vivo [150,168]. Indeed, HOXC10 overexpression enhances tube formation, migration, and proliferation of Human Umbilical Vein Endothelial Cells (HUVEC, a specific type of endothelial cells) and neovascularization in the Chicken Chorioallantoic Membrane (CAM) in vivo assay \{Tan, 2018 \#9161\}.

Three genes from the HOXA cluster have also been reported to have an important role in resistance to therapy. Specifically, HOXA9 and HOXA10 have been associated with decreased sensitivity to the chemotherapy drug temozolomide (TMZ) in GBM patients, a finding that was further supported by a causal relationship in cell lines $[169,124,150]$, and HOXA5 also decreased sensitivity to radiotherapy in vitro and in vivo [149].

In vivo, three genes of the "nine paralogues", HOXA9, HOXB9, and HOXC9, were shown to promote oncogenesis, as shown by the increased tumour volumes in subcutaneous GBM mouse models $[153,150,165]$. In clinically more relevant orthotopic models (i.e., based on intracranial implantation of GBM cells in mice), $H O X A 5, A 9, A 10, A 13, C 6$, and $C 9$ expression increased the GBM-associated death rate $[146,161,150,165,154,149]$. Particularly interesting in these orthotopic models was HOXA9 
and HOXA5, which increased the resistance to TMZ-based chemotherapy and radiotherapy, respectively, as indicated by the lower overall survival (OS) of mice bearing tumours positive for these HOX genes, as compared to negative tumours [150]. Interestingly, HOXA9 overexpression in non-neoplastic human astrocytes induced their transformation when intracranially implanted, as shown by tumour formation and tumour-related death in $70 \%$ of the tested mice. Moreover, histological examination of the tumours formed after intracranial injection showed the presence of characteristic hallmarks of malignant gliomas. Remarkably, this tumorigenic capacity is not observed when cells are implanted subcutaneously, which stresses the critical importance of the tumour microenvironment.

Although most HOX genes display pro-tumour functions, a few exceptions have been reported. HOXB1 has tumour suppressive functions in GBM, by decreasing cell viability and promoting apoptosis in vitro [159]. HOXD10 decreases the invasive potential of GBM cell lines [170,171], and HOXA11 increases the sensitivity of GBM cell lines to chemotherapy and radiotherapy [147].

The functional impact of approximately half of HOX genes in GBM has already been described, particularly concerning the HOXA cluster. This stronger emphasis in HOXA genes could be partly explained due to the fact that they are on chromosome 7, which is frequently amplified in GBM, although HOXA gene copy number alterations have not been consistently associated with its expression $[122,150,149,161]$. Future studies on the roles of the other HOX genes in glioma will be critical to provide a more complete picture of their implication in these tumours. Additionally, considering the enormous heterogeneity observed between different glioma tumours, studies in glioma subtypes other than GBM will be of critical importance. Moreover, some of the previous findings could be consolidated by using: i) more biologically relevant models based on gene silencing, instead of overexpression approaches in which gene expression may reach unrealistic levels; ii) more clinically relevant patient-derived primary cell cultures, as opposed to cell lines that have been established and cultured for many years and that no longer faithfully reflect the original tumour; iii) stem cell cultures in serum-free conditions (e.g., neurospheres) that could be particularly useful to understand whether HOX roles are more relevant in the glioma stem-cell subpopulation or in more differentiated cells; and iv) 3D cultures (e.g., organoids) that better mimic the tumour microenvironment, endogenous cell organization, and organ structures, which could help might be relevant to better understand the role of HOX genes in more complex contexts.

\subsection{Molecular bases of HOX gene deregulation in glioma}

It is now clear that in glioma, the HOX gene activation pattern does not follow the coordinated collinear expression observed during normal embryonic development (described above). This process 
1 is complex, which in addition to the deregulation of the main processes controlling HOX expression

2 in normal contexts (described above) also involves epigenetic alterations, gene copy number

3 variations, and direct activation by other transcriptional complexes.

4 Copy number variations (CNV) at HOX loci:

5 A pathognomonic characteristic of GBM IDH-wildtype is chromosome 7 trisomy (considered an 6 early event in gliomagenesis) and chromosome 10 monosomy. As the HOXA locus is on chromosome

7 7, chromosome 7 trisomy might increase HOXA gene expression in these patients. Indeed, a 8 correlation was observed between chromosome 7 gain and HOXA1, HOXA4 [172], and HOXA5 [149] expression in GBM and IDH-wildtype patients. However, this is not true for all HOXA genes because no correlation was observed between CNV and expression of HOXA2 [172], HOXA9 [150], HOXA10 [161], and HOXA13 [172]. This issue has been less studied at the other HOX clusters. Nonetheless, it was recently shown that overexpression of eight HOX genes distributed over the HOXB, C and D clusters was CNV-independent in IDH-wildtype samples [172]. Altogether, these observations support the hypothesis that $\mathrm{CNV}$, if present, are not the main driving force of HOX gene overexpression in aggressive glioma.

Protein- or miRNA-directed targeting of HOX genes: Several miRNAs have been shown to negatively regulate HOX genes in GBM. For example, HOXB1 is a target of hsa-miR-3175 [148], and HOXD10 is a target of hsa-miR-21 [162], hsa-miR-10b [134], and hsa-miR-23a [149,160] in GBM. Moreover, hsa_circ_0074362 (circular RNA) was shown to act as a hsa-mir-1236-3p sponge to promote $H O X B 7$ expression in GBM [141].

Protein-gene promoter interactions is another well-known mechanism governing HOX deregulation. Gallo et al. [161] described that MLL protein, which contributes to HOXA gene regulation in haematopoiesis and leukemic cells, directly interacts with the promoter of HOXA10 in glioblastoma stem cells. HOXA10 protein then interacts with the promoter region of HOXA7 and HOXC10, activating their transcription [161].

Epigenetic alterations

As depicted in section 2, Polycomb group proteins and the associated H3K27me3 mark are key players in the control of HOX expression during normal development. A large number of studies have highlighted that bona-fide polycomb target genes are also more likely to gain aberrant DNA methylation in cancer cells [Ohm et al. 2007; Deneberg et al. 2011; 176]. Thus, not surprisingly, aberrant DNA methylation is a well-documented signature at HOX loci in glioma.

This was first observed by Martinez et al. [174] who evaluated the DNA methylation profile of 1505 CpGs sites, covering 807 genes, in 87 GBM patient samples. They identified 25 genes that were 
hypermethylated and 7 that were hypomethylated in at least $20 \%$ of samples. Among the 25

2 hypermethylated genes, 3 were HOXA genes: HOXA11 (hypermethylated in 51\% of GBM), HOXA9

3 (in 44\%), and HOXA5 (in 20\%). Genome-wide analyses confirmed that the four HOX clusters tend

4 to be hypermethylated in GBM and IDH-wildtype glioma, when compared to non-tumour brain

5 samples (Kurscheid et al. [175]. This reminds the observation that hypermethylation of homeobox

6 gene promoters, including HOX genes, is emerging as a pan-cancer signature [176]. Interestingly, the

7 level of DNA methylation alteration can vary between genes and patients. In 2012, Di Vinci et al.

8 [177] analysed DNA methylation of $H O X A 3, A 7, A 9$, and $A 10$ in 63 glioma and found patient-specific

9 DNA methylation patterns. This finding was validated by Pojo et al. [150] for HOXA9. HOXA3 was

10 the gene with the highest DNA methylation levels in GBM, while $H O X A 7, A 9$, and $A 10$ presented 11 lower levels [177].

12 Gain of expression associated with gain of methylation at HOX loci is not in line with the canonical 13 inhibitory effect of DNA promoter methylation on gene transcription. Refined analyses that integrated

DNA methylation and strand-oriented expression patterns in glioma patient samples [172] provided some explanations to this apparent paradox. Specifically, for several genes, ectopic expression was associated with $\mathrm{CpG}$ islands/promoters that gained methylation at their borders, while their transcription start sites (TSS) remained methylation-free. At other genes, extensive methylation of their main $\mathrm{CpG}$ islands/promoter was associated with the use of an alternative promoter. For instance, in IDH-wildtype glioma, HOXC11 transcription initiated from an unmethylated alternative promoter located $5 \mathrm{~kb}$ upstream the canonical, aberrantly methylated promoter [172]. This picture becomes even more complex in the case of chromosome 7 gain. Kurscheid et al. [175] suggested that hypermethylation of the HOXA cluster could compensate the CNV at this cluster in GBM cells with low expression level (HOX-low), while key CpG sites located in the HOXA locus could escape this hypermethylation phenotype in HOX-high GBM cells. Specifically, they showed that a CpG island located at the HOXA10 non-canonical promoter escape to hypermethylation in HOX-high GBM cells.

Court et al. [172] provided evidences that besides the DNA methylation gain, HOX clusters in IDHwildtype glioma samples are characterized also by dramatic reduction of H3K27me3. Given the importance of this mark for HOX gene repression in normal brain [59] (as previously detailed in section 2), its loss might be crucial for their aberrant expression in aggressive glioma. A study by Costa et al. [122] suggests that alteration of the PI3K pathway could be involved in this process. They showed that PTEN-dependent activation of the PI3K pathway resulted in AKT-mediated phosphorylation of EZH2, the catalytic subunit of the PRC2 complex, that suppresses H3K27me3, leading to derepression of previously silenced HOXA genes. Moreover, they demonstrated that this 
process is reversible, because PI3K pathway pharmacological inhibition abolished HOXA gene overexpression in GBM cells. Court et al. [172] also proposed that loss of H3K27me3 at HOX genes is a consequence of genome-wide hypomethylation that characterizes cancer cells. In the mouse, widespread DNA methylation depletion triggers H3K27me3 redistribution $[179,180]$ that in turn leads to dramatic loss of $\mathrm{H} 3 \mathrm{~K} 27 \mathrm{me} 3$ and ectopic expression at a subset of polycomb target genes, including Hox clusters [180].

\section{Alterations in 3D chromatin structure and HOX deregulation in glioma}

Recent studies revealed that alteration in 3D genome organisation is also a feature of glioma cells. Flavahan et al. [178] showed in IDH-mutant glioma that hypermethylation of CTCF binding sites leads to the decrease in the recruitment of CTCF insulator proteins. Therefore, the resulting loss of insulation between TADs leads to aberrant gene activation, such as the oncogene PDGFRA [178]. The generation of 3D genome maps by in situ Hi-C in glioblastoma stem cells (GSCs) also stressed that 3D structures are altered in these cells, and also between different GSCs lines, providing a layer of glioblastoma inter-patient heterogeneity (Johnston et al. 2019). Whether this type of alteration also contributes to HOX deregulation in glioma is not documented. However, given the importance of remote regulatory regions and $3 \mathrm{D}$ structure in the control of HOX expression during normal development, it is critical to further explore this issue.

In conclusion, HOX clusters display various molecular alterations in glioma cells. To which extent and how each of these alterations contributes to HOX genes gain of expression remain to be determined. Comprehensive studies in which CNVs, DNA methylation, histone modifications and gene expression are analysed in an integrative manner at HOX clusters are now required to decipher the interplay between these molecular signatures in glioma samples and to identify the causes of their alterations. Interestingly, the finding that the HOXA cluster is over-activated in GBM concomitantly with specific HOXB, C and D genes $[125,124,122]$ suggests again that a complex and inter-dependent mechanism of HOX gene regulation might exist in glioma.

\subsection{HOX target genes}

As HOX proteins are transcription factors and their targets might be the true biological effectors of their functional roles, several authors have tried to identify these targets in GBM. Potential direct or indirect targets of HOXA5, A9, A10, A11, A13, B9, C6, C9, C10, D9, and D10 were already described, and direct targets were confirmed by chromatin immunoprecipitation (ChIP) for HOXA9, A10, B9, C9, and C10. For the sake of comprehensiveness, a brief summary of some potential HOX 
targets genes is presented in the following paragraphs (the complete list of potential targets can be found in the original publications).

\section{$\underline{\text { HOXA5 }}$}

Cimino et al. [149] identified 692 differentially expressed genes (144 upregulated and 412 downregulated) upon HOXA5 expression in mouse GBM cell lines. By combining this information with data on genes containing HOXA5 binding sequences found by ChIP-seq analysis in human carcinoma cells, they identified 136 common genes (46 upregulated and 90 downregulated). Pathway enrichment analysis of the 46 upregulated genes (e.g. ASPM, AURKA, BLM, CCNB1, CDC25C, CDKN3, CLSPN, FOXM1, INCENP, MDK, and PCNA) showed that many were implicated in the cell cycle and DNA damage pathways, fitting well with the findings from other studies implicating HOXA5 as a pro-tumour factor.

\section{$\underline{\text { HOXA9 }}$}

Microarray analysis of GBM cell lines (U87, U251, and a primary GBM cell line) in which HOXA9 is overexpressed or silenced, identified more than 3000 deregulated transcripts in U87 and U251 cells, and over 6000 transcripts in the primary GBM cell line [182,150]. Only 61 were altered (18 upregulated and 43 downregulated) in all three cell lines, indicating that gene regulation by HOXA9 in GBM follows a cell-specific pattern. Overexpression of HOXA9 in normal human astrocytes led to the differential expression of more than 500 transcripts, from which 256 were common to at least one of the GBM cell lines (77 upregulated and 179 downregulated) [182,150]. Pathway and gene set enrichment analyses showed that the HOXA9 differentially expressed genes were enriched, for example, in inflammatory response, cell adhesion/migration, stem cells, DNA repair, and cycling genes. Moreover, HOXA9-overexpressing cells showed deregulation of the mismatch repair (MMR) and BCL2 DNA repair systems, as indicated by downregulation of PMS2 and MSH6, and upregulation of BCL2 proteins. Later, Xavier-Magalhães et al. [183] identified HOTAIR, a lncRNA located at the HOXC cluster with oncogenic functions in GBM, as a direct target (positive regulation) of HOXA9 by ChIP-PCR. Interestingly, HOTAIR, the first described lncRNA to present trans-acting functions, negatively regulates HOXD genes in physiological conditions [63]. Whether this mechanism also occurs or is deregulated in glioma remains to be explored. Recently, Gonçalves et al. [184] demonstrated that WNT6, a ligand and activator of the WNT pathway, which displays oncogenic functions in GBM [185], is transcriptionally regulated by HOXA9, identifying a novel link between HOX and WNT signalling.

\section{$\underline{\text { HOXA10 }}$}


1 Gallo et al. [161] identified, by ChIP-on-chip analysis, 261 direct HOXA10 targets in GBM stem

2 cells, and validated 7 of them by ChIP-quantitative PCR (HOXA7, HOXC10, HOXC11, HOXC12, HOXB13, CBX6, TERT, FGF17, JAG2, and NODAL). Enrichment analysis identified significant enrichment for genes involved in processes as growth factor activity, homeobox, CHROMO domain, cytokine, and actin cytoskeleton organization. Additionally, Kim et al. [169] showed that, in GBM cell lines, HOXA10 regulates, in a PI3K-independent manner, PTEN nuclear function (with a different function than the tumour suppressive PTEN cytoplasmic function) through induction of EGR1, which consequently upregulates RAD51 expression, impairing the homologous recombination DNA repair system. In agreement, HOXA10 silencing increased $\gamma-\mathrm{H} 2 \mathrm{AX}$, a marker of DNA double strand breaks, in GBM cells [169].

\section{HOXA11}

Silencing of HOXA11, which presents tumour suppressive functions in GBM, led to more than twofold changes in the expression of 62 genes (11 upregulated and 51 downregulated) in GBM cells [147]. This gene list was significantly enriched in genes implicated in the regulation of growth and mitochondrion activity. Specifically, TGFBR2, CRIM1, DPYSL2, and CRMP1 were downregulated upon HOXA11 silencing, whereas TXNIP, CD22, EPCAM, MMP3, and SLC16A6 were upregulated. Duan et al. [146] analysed the gene expression profiling data from The Cancer Genome Atlas (TCGA), Rembrandt and the Chinese Glioma Genome Atlas (CGGA) datasets to identify genes showing high correlation (positive or negative) with HOXA13, in order to discover its potential targets in GBM. Positively correlated genes belonged mainly to pathways related to cancer, focal adhesion, WNT pathway, and cell cycle. On the other hand, negatively correlated genes were mostly implicated in the MAPK, ERBB, VEGF, PPAR, and mTOR signalling pathways. In vitro, Duan et al. [146] observed that HOXA13 silencing led to decreased levels of nuclear $\beta$-catenin and of phosphorylated SMAD2 and SMAD3. Conversely, the level of phosphorylated $\beta$-catenin was increased in the cytoplasm, which is indicative of WNT pathway inactivation. Similarly, Yan et al. [154] suggested that the WNT pathway is regulated by HOXC6, through downregulation of WIF-1, a WNT antagonist.

$\underline{\operatorname{HOXB} 9}$

TGF 1 was identified as a direct target of HOXB9 by ChIP-PCR, leading to increased levels of CD133, OCT4, NESTIN, BMI-1, and, similarly to HOXA13, phosphorylated SMAD2 [153].

$\underline{\mathrm{HOXC} 9}$ 
HOXC9 has a role in the regulation of autophagy, and DAPK1 was identified as a direct target (negative regulation) by ChIP-quantitative PCR and luciferase reporter assays [165]. HOXC9 silencing released DAPK1 transcriptional repression, resulting in activation of the DAPK1-Beclin1 pathway and autophagy induction in GBM cells. In agreement, the expression of autophagy protein (i.e., ATG7, ATG5, ATG3, and LC3B) was induced by HOXC9 silencing, while no alterations were found in apoptotic-related proteins (e.g., caspase 9/3 and BCL2) [165].

\section{$\underline{\mathrm{HOXC} 10}$}

In the context of the growing interest in understanding the complex interactions between cancer and immune cells, a recent study showed HOXC10 plays a role in tumour immune evasion [156]. Indeed, HOXC10 silencing in GBM cell lines decreases the expression of proteins involved in tumour immunosuppression (i.e., TGFB2, PDL2, CCL2, and TDO2). PDL2 and TDO2 were identified as direct targets of HOXC10 in these cells by ChIP-quantitative PCR [156]. Moreover, Tan et al. [168] reported a significant enrichment of HOXC10-correlated genes and angiogenic gene sets in GBM patients. Mechanistically, they found that HOXC10 modulates GBM angiogenesis through direct regulation of VEGFA (ChIP-quantitative PCR and luciferase reporter assays). Moreover, they showed that PRMT5 and WDR5, which regulate histone post-translational modifications, are required for HOXC10-mediated VEGFA upregulation [168]. Thus, although bevacizumab (anti-VEGFA monoclonal antibody) does not significantly improve OS in patients with GBM [186,187], it significantly decreased the growth of HOXC10-overexpressing intracranial tumours in mice and efficiently impaired their angiogenic capacity [168]. This suggests that HOXC10 may be a clinically useful biomarker of bevacizumab response in GBM.

$\underline{\text { HOXD9 }}$

Tabuse et al. [126] performed gene microarray analysis to identify potential HOXD9 target genes in GBM cell lines. $H O X D 9$ silencing led to upregulation of some genes known to be relevant in cancer (e.g., TRAIL, ANGPTL4, and SEMA4D), and downregulation of others (e.g., BRCA1, TGFB1, and $B C L 2)$. Interestingly, BCL2 was also positively associated with another group 9 paralogue, HOXA9, in GBM [150].

\section{$\underline{\text { HOXD10 }}$}

Finally, it has been repeatedly reported that, in GBM cell lines, HOXD10 acts by negatively regulating the metastatic-related protein $\mathrm{RHOC}[173,170,171]$ and matrix metalloproteinases, such as MMP14 [160,145,171]. 
Overall, these findings suggest that although the transcriptional target genes of the different HOX proteins mostly do not overlap, they frequently lead to transcriptional programmes that regulate similar molecular processes/pathways (e.g., cell cycle, death, migration/invasion, and inflammation are pathways commonly affected across studies testing different HOX genes), all of which are particularly relevant in the context of cancer. Moreover, it is not surprising that many of the identified targets might be cell type-dependent, as several factors are known to contribute to the diversity and specificity of HOX protein activity, leading to highly dynamic, context-specific HOX transcriptional activation, and to their functional diversification. Indeed, it was described that i) there are many transcriptional partners - HOX cofactors and collaborators - that also present cell type-specific expression patterns [188,189]; ii) the binding between HOX proteins and their cofactors might be context-dependent [190], and different combinations may lead to distinct binding specificities, contributing to the spatiotemporal specificity of HOX proteins; and iii) chromatin accessibility and DNA shape, which may vary between cells, also showed to confer HOX specificity [191]. Bioinformatic studies are needed to cross the thousands of genes and dozens of pathways differentially regulated by each of the 39 HOX proteins in glioma, to better integrate the data. More studies are also needed to identify HOX targets in particular glioma cells of the various tumour niches (e.g., in glioma stem cells versus more differentiated glioma cells; and proliferating versus invading cells), which may be relevant for the design of new therapeutic interventions.

\subsection{Clinical implications of HOX genes}

In 2008, Murat et al. [124] suggested that a HOX-dominated gene signature, which included HOXA2, $A 3, A 5, A 7, A 9, A 10, C 6, D 4, D 8$, and $D 10$, was an independent predictive factor of therapy resistance in GBM. In 2010, Costa et al. [122] showed that HOXA1, A2, A3, A4, A5, A7, A9, B7, and C6 are overexpressed in GBM compared with non-tumour brain samples, and found that HOXA9 expression was associated with poor prognosis, independently of other well-known prognostic factors [122]. Indeed, in patients with MGMT promoter methylation (associated with better prognosis), HOXA9 could still identify a subset of patients with poor prognosis [122]. Moreover, the combination of HOXA9 and HOXA10 expression was also associated with shorter OS in paediatric patients with GBM [123]. More recently, the prognostic value of HOXA9 in GBM was consolidated in additional patient cohorts [150]. Although the DNA methylation levels of $H O X A 3, A 9$, and $A 10$ positively correlate with WHO grading, HOXA9 and HOXA10 DNA methylation has been associated with better prognosis in patients with GBM [177]. Conversely, $\operatorname{HOXD} 8, D 13$, and $C 4$ hypermethylation was observed in short-term ( $<1$ year OS) GBM survivors [192]. Additionally, HOXA5, A10, A13, B9, C4, $C 6, C 9, C 10$, and $D 4$ were individually associated with shorter OS in patients with GBM 
[149,146,153,157,156,124,165,154,158,162]. Among them, HOXB9 and HOXD4 are also associated with shorter OS in patients with glioma, grade II glioma (HOXD4 only), and grade III glioma $[153,158]$. In line with their tumour suppressive functions in GBM, HOXA11 and HOXBI were individually associated with longer OS in patients with GBM [159,147].

In the future, these very interesting results should be updated and put into perspective in the light of the new 2016 WHO classification of gliomas that includes molecular features to differentiate glioma subtypes. Moreover, the validation of the prognostic value of HOX genes in several independent, large, and robust datasets, preferably using more robust multivariable statistical analysis, will be of paramount importance to potentially bring HOX genes into the clinics.

Recently, drugs interfering with the PRC2 complex emerged as promising agents for cancer treatment, as the FDA recently-approved drug Tazemetostat for epithelioid sarcoma. While the overall benefit in other tumour types remains to be determined, it is important to consider that PRC2 inhibitors might lead to decreased $\mathrm{H} 3 \mathrm{~K} 27 \mathrm{me} 3$ at $\mathrm{HOX}$ loci, potentially leading to their overactivation. Nonetheless, Khan et al. [193] recently demonstrated that, in opposition to the classical view that PRC2 is the major transcriptional repressive complex of HOX genes, the knockdown of some PRC2 subunits, such as SUZ12, EZH2, or EED, in mouse F9 teratocarcinoma cells, globally decreased H3K27me3 levels, but not in HOX clusters, where curiously H3K27me3 increased instead. Indeed, although decreased enrichment of the PRC2 complexes was observed at HOX loci upon SUZ12, EZH2, or EED silencing, the expression of HOX genes did not increase [193]. MTF2 was pointed as the potential responsible molecule for $\mathrm{H} 3 \mathrm{~K} 27 \mathrm{me} 3$ enrichment in HOX loci in the absence of PRC2 [193]. Whether a similar effect and underlying mechanism is more generally observed in cancer, including in GBM, remains to be investigated. Additionally, Li et al. [194] described that AC1Q3QWB (AQB), a small-molecule compound, is a selective disruptor of HOTAIR-EZH2 interactions, blocking PRC2 recruitment to target genes, presenting a pre-clinical potential worth of further evaluation for the treatment of GBM and breast cancers with high levels of EZH2 and HOTAIR. Indeed, AQB administration to orthotopic mice models of GBM and breast cancer significantly decreased tumour aggressiveness. In vitro and in vivo, AQB treatment resulted in increased HOXD10 expression, among other PRC2 target genes. Further experiments in orthotopic mice models of a breast cancer and a GBM patient-derived xenograft (PDX) demonstrated that the combinatorial treatment of AQB with an indirect inhibitor of EZH2 (DZNep) significantly reduced tumour growth and increased mice OS, respectively. However, besides the unknown role of HOXD10 in GBM, and whether it acts as a tumour suppressor or an oncogene, the complete transcriptional profile of HOX genes before and after treatment with these PRC2-targeting compounds remains 
unknown. Moreover, drugs like DZNep are now recognized as global histone methylation inhibitors, rather than a H3K27-specific one [195]. These studies emphasize that, in the context of precision medicine, the global identification of the transcriptional signatures of a specific cancer patient should be considered to aim in the decision for particular targeted therapies, as the uninformed use of these agents may lead to pro-tumour effects that will harm a subset of patients.

\section{Conclusions and future perspectives}

Deregulation of HOX genes is a common phenomenon in malignant primary brain tumours, and most findings reported to date associate HOX gene overexpression with oncogenic functions in glioma. These include critical cancer hallmarks, such as increased cell viability, invasion, migration, angiogenesis, stem cell capacity, and therapy resistance, and decreased cell death/apoptosis (summarized in Fig. 4). Of note, all these studies have not explored the potential role of HOX genes in influencing interactions between cancer cells and those of the tumour microenvironment. Interestingly, Bertolini et al (2019) reported that GBM neurospheres influence non-neoplastic cells from their microenvironment by delivering HOXA7 and HOXA10 via large oncosomes. This large oncosomes, which were abundantly found in the serum of patients with shorter OS, are able to reprogram recipient cells to proliferate, grow as spheres and to migrate. It should also be interesting to investigate how HOX genes may influence tumour immune responses, both in treatment-naïve contexts and under treatment, particularly with immunotherapies. Interestingly, Pojo et al. [150] showed that HOXA9 downregulates genes involved in antigen processing/presentation in various human GBM [150]. Moreover, Li et al. [156] found that HOXC10 positively regulates genes involved in tumour immunosuppression in GBM, including PDL2 and TDO2. Together with recent reports in ovarian cancer linking HOXA9 to an M2 macrophage tumour-promoting phenotype and reduction of $\mathrm{CD}^{+}$lymphocyte infiltration [196], these findings strengthen the idea that HOX genes may play an important role in the regulation of the immune system in the tumour microenvironment.

Considering the critical functional roles and putative prognostic value of specific HOX genes in cancer, including in malignant glioma, and their complex molecular interactions with upstream regulators and downstream targets, it becomes clear that additional studies are necessary to better understand how HOX operate in glioma, and whether they may be therapeutically explored in the clinics. For example, future studies will be critical to identify the whole molecular networks interacting with HOX genes in brain tumours, by generating genome-wide binding profiles to identify their targets, their upstream binding factors (including lncRNA and miRNAs), and protein partners, as well as HOX-specific DNA methylation studies to explore both transcription factor-related and independent HOX functions. These integrated approaches will broaden our understanding of HOX 
1 roles in normal and abnormal development and malignant transformation, may allow the 2 identification of potentially targetable players suitable for therapeutic intervention, and/or to the 3 development of clinically useful diagnostic/prognostic tools in a paradigm of precision medicine. In 4 addition, it is still unclear whether HOX genes have causative roles in gliomagenesis, or whether their 5 alterations are a bystander consequence of malignant transformation, as well as whether HOX6 directed therapies may be useful for the treatment of glioma and other HOX-driven cancers (e.g., 7 acute myeloid leukaemia). These open questions will continue to feed the researchers' interest for 8 many years. 
2 1. Bateson W (1894) Materials for the study of variation: treated with especial regard to discontinuity in the origin of species. Macmillan and Co, London, New York

2. Bridges CB (1921) Current maps of the location of the mutant genes of Drosophila melanogaster. Proc Natl Acad Sci U S A 7 (4):127

3. Kaufman TC, Seeger MA, Olsen G (1990) Molecular and genetic organization of the antennapedia gene complex of Drosophila melanogaster. In: Advances in genetics, vol 27. Elsevier, pp 309-362

4. Lewis EB (1978) A gene complex controlling segmentation in Drosophila. In: Genes, Development and Cancer. Springer, pp 205-217

5. Schneuwly S, Klemenz R, Gehring WJ (1987) Redesigning the body plan of Drosophila by ectopic expression of the homoeotic gene Antennapedia. Nature 325 (6107):816

6. Qian Y, Billeter M, Otting G, Müller M, Gehring W, Wüthrich K (1989) The structure of the Antennapedia homeodomain determined by NMR spectroscopy in solution: comparison with prokaryotic repressors. Cell 59 (3):573-580

7. Hui C-c, Suzuki Y, Kikuchi Y, Mizuno S (1990) Homeodomain binding sites in the 5 ' flanking region of the Bombyx mori silk fibroin light-chain gene. J Mol Biol 213 (3):395-398

8. Kissinger CR, Liu BS, Martin-Blanco E, Kornberg TB, Pabo CO (1990) Crystal structure of an engrailed homeodomain-DNA complex at $2.8 \mathrm{~A}$ resolution: a framework for understanding homeodomain-DNA interactions. Cell 63 (3):579-590. doi:10.1016/0092-8674(90)90453-I

9. Ekker SC, Young KE, von Kessler DP, Beachy P (1991) Optimal DNA sequence recognition by the Ultrabithorax homeodomain of Drosophila. The EMBO Journal 10 (5):1179-1186

10. Benson GV, Nguyen TH, Maas RL (1995) The expression pattern of the murine Hoxa-10 gene and the sequence recognition of its homeodomain reveal specific properties of Abdominal B-like genes. Mol Cell Biol 15 (3):1591-1601. doi:10.1128/mcb.15.3.1591

11. Pearson JC, Lemons D, McGinnis W (2005) Modulating Hox gene functions during animal body patterning. Nature reviews Genetics 6 (12):893-904. doi:10.1038/nrg1726

12. Takahashi Y, Hamada J, Murakawa K, Takada M, Tada M, Nogami I, Hayashi N, Nakamori S, Monden M, Miyamoto M, Katoh H, Moriuchi T (2004) Expression profiles of 39 HOX genes in normal human adult organs and anaplastic thyroid cancer cell lines by quantitative real-time RT-PCR system. Exp Cell Res 293 (1):144-153

13. Yamamoto M, Takai D, Yamamoto $F$ (2003) Comprehensive expression profiling of highly homologous 39 hox genes in 26 different human adult tissues by the modified systematic multiplex RT-pCR method reveals tissue-specific expression pattern that suggests an important role of chromosomal structure in the regulation of hox gene expression in adult tissues. Gene Expr 11 (34):199-210

14. Morgan R (2006) Hox genes: a continuation of embryonic patterning? Trends in genetics : TIG 22 (2):67-69. doi:10.1016/j.tig.2005.11.004

15. Neville SE, Baigent SM, Bicknell AB, Lowry PJ, Gladwell RT (2002) Hox gene expression in adult tissues with particular reference to the adrenal gland. Endocr Res 28 (4):669-673

16. Boncinelli E, Simeone A, Acampora D, Gulisano M (1993) Homeobox genes in the developing central nervous system. Ann Genet 36 (1):30-37

17. Young JJ, Grayson P, Tabin CJ (2019) Developmental Biology: Hox Timing Determines Limb Placement. Current biology : CB 29 (2):R52-R54. doi:10.1016/j.cub.2018.11.068

18. Deschamps J, van Nes J (2005) Developmental regulation of the Hox genes during axial morphogenesis in the mouse. Development 132 (13):2931-2942

19. Duverger O, Morasso MI (2008) Role of homeobox genes in the patterning, specification, and differentiation of ectodermal appendages in mammals. J Cell Physiol 216 (2):337-346 
20. Garcia-Fernàndez J (2005) The genesis and evolution of homeobox gene clusters. Nature Reviews Genetics 6 (12):881

21. Rezsohazy R, Saurin AJ, Maurel-Zaffran C, Graba Y (2015) Cellular and molecular insights into Hox protein action. Development 142 (7):1212-1227

22. Grier DG, Thompson A, Kwasniewska A, McGonigle GJ, Halliday HL, Lappin TR (2005) The pathophysiology of HOX genes and their role in cancer. The Journal of pathology 205 (2):154-171. doi:10.1002/path.1710

23. Krumlauf $R$ (1994) Hox genes in vertebrate development. Cell 78 (2):191-201

24. Scott MP (1992) Vertebrate homeobox gene nomenclature. Cell 71 (4):551-553

25. Kmita M, Duboule D (2003) Organizing axes in time and space; 25 years of colinear tinkering. Science 301 (5631):331-333

26. Montavon T, Soshnikova N (2014) Hox gene regulation and timing in embryogenesis. Semin Cell Dev Biol 34:76-84. doi:10.1016/j.semcdb.2014.06.005

27. Noordermeer D, Duboule D (2013) Chromatin architectures and Hox gene collinearity. In: Current topics in developmental biology, vol 104. Elsevier, pp 113-148. doi:10.1016/B978-0-12416027-9.00004-8

28. Duboule D (2007) The rise and fall of Hox gene clusters. Development 134 (14):2549-2560

29. Quinonez SC, Innis JW (2014) Human HOX gene disorders. Mol Genet Metab 111 (1):4-15. doi:10.1016/j.ymgme.2013.10.012

30. Marshall H, Studer M, Pöpperl H, Aparicio S, Kuroiwa A, Brenner S, Krumlauf R (1994) A conserved retinoic acid response element required for early expression of the homeobox gene Hoxb-1. Nature 370 (6490):567

31. Puschel AW, Balling R, Gruss P (1991) Separate elements cause lineage restriction and specify boundaries of Hox-1.1 expression. Development 112 (1):279-287

32. Gentile C, Kmita M (2018) The remote transcriptional control of Hox genes. The International journal of developmental biology 62 (11-12):685-692

33. Spitz F, Gonzalez F, Peichel C, Vogt TF, Duboule D, Zákány J (2001) Large scale transgenic and cluster deletion analysis of the HoxD complex separate an ancestral regulatory module from evolutionary innovations. Genes Dev 15 (17):2209-2214

34. Tümpel S, Cambronero F, Sims C, Krumlauf R, Wiedemann LM (2008) A regulatory module embedded in the coding region of Hoxa2 controls expression in rhombomere 2. Proceedings of the National Academy of Sciences 105 (51):20077-20082

35. Ahn $Y$, Mullan HE, Krumlauf R (2014) Long-range regulation by shared retinoic acid response elements modulates dynamic expression of posterior Hoxb genes in CNS development. Dev Biol 388 (1):134-144

36. Spitz F, Gonzalez F, Duboule D (2003) A global control region defines a chromosomal regulatory landscape containing the HoxD cluster. Cell 113 (3):405-417

38. Tarchini B, Duboule D (2006) Control of Hoxd genes' collinearity during early limb development. Dev Cell 10 (1):93-103

39. Andrey G, Montavon T, Mascrez B, Gonzalez F, Noordermeer D, Leleu M, Trono D, Spitz F, Duboule D (2013) A switch between topological domains underlies HoxD genes collinearity in mouse limbs. Science 340 (6137):1234167

41. Berlivet S, Paquette D, Dumouchel A, Langlais D, Dostie J, Kmita M (2013) Clustering of tissuespecific sub-TADs accompanies the regulation of HoxA genes in developing limbs. PLoS genetics 9 (12):e1004018

42. Neijts R, Amin S, Van Rooijen C, Tan S, Creyghton MP, De Laat W, Deschamps J (2016) Polarized regulatory landscape and Wnt responsiveness underlie Hox activation in embryos. Genes Dev 30 (17):1937-1942 
43. Nolte $C$, Jinks T, Wang X, Pastor MTM, Krumlauf R (2013) Shadow enhancers flanking the HoxB cluster direct dynamic Hox expression in early heart and endoderm development. Dev Biol 383 (1):158-173

44. Denker A, De Laat W (2016) The second decade of 3C technologies: detailed insights into nuclear organization. Genes Dev 30 (12):1357-1382

45. Dixon JR, Selvaraj S, Yue F, Kim A, Li Y, Shen Y, Hu M, Liu JS, Ren B (2012) Topological domains in mammalian genomes identified by analysis of chromatin interactions. Nature 485 (7398):376

46. Nora EP, Lajoie BR, Schulz EG, Giorgetti L, Okamoto I, Servant N, Piolot T, van Berkum NL, Meisig $J$, Sedat J (2012) Spatial partitioning of the regulatory landscape of the X-inactivation centre. Nature 485 (7398):381

47. Neijts R, Deschamps J (2017) At the base of colinear Hox gene expression: cis-features and transfactors orchestrating the initial phase of Hox cluster activation. Dev Biol 428 (2):293-299

48. Bonev B, Cohen NM, Szabo Q, Fritsch L, Papadopoulos GL, Lubling Y, Xu X, Lv X, Hugnot J-P, Tanay A (2017) Multiscale 3D genome rewiring during mouse neural development. Cell 171 (3):557-572. e524. doi:10.1016/j.cell.2017.09.043

49. Delpretti S, Montavon T, Leleu M, Joye E, Tzika A, Milinkovitch M, Duboule D (2013) Multiple enhancers regulate Hoxd genes and the Hotdog LncRNA during cecum budding. Cell reports 5 (1):137-150

50. Jin F, Li Y, Dixon JR, Selvaraj S, Ye Z, Lee AY, Yen C-A, Schmitt AD, Espinoza CA, Ren B (2013) A high-resolution map of the three-dimensional chromatin interactome in human cells. Nature 503 (7475):290

51. Narendra V, Bulajić M, Dekker J, Mazzoni EO, Reinberg D (2016) CTCF-mediated topological boundaries during development foster appropriate gene regulation. Genes Dev 30 (24):2657-2662 52. Narendra V, Rocha PP, An D, Raviram R, Skok JA, Mazzoni EO, Reinberg D (2015) CTCF establishes discrete functional chromatin domains at the Hox clusters during differentiation. Science 347 (6225):1017-1021

53. Phillips-Cremins JE, Corces VG (2013) Chromatin insulators: linking genome organization to cellular function. Mol Cell 50 (4):461-474

54. Phillips-Cremins JE, Sauria ME, Sanyal A, Gerasimova TI, Lajoie BR, Bell JS, Ong C-T, Hookway TA, Guo C, Sun Y (2013) Architectural protein subclasses shape 3D organization of genomes during lineage commitment. Cell 153 (6):1281-1295

55. Montavon T, Soshnikova N, Mascrez B, Joye E, Thevenet L, Splinter E, de Laat W, Spitz F, Duboule $D$ (2011) A regulatory archipelago controls Hox genes transcription in digits. Cell 147 (5):1132-1145 56. Bernstein BE, Mikkelsen TS, Xie X, Kamal M, Huebert DJ, Cuff J, Fry B, Meissner A, Wernig M, Plath K (2006) A bivalent chromatin structure marks key developmental genes in embryonic stem cells. Cell 125 (2):315-326

57. Soshnikova N, Duboule D (2009) Epigenetic temporal control of mouse Hox genes in vivo. Science 324 (5932):1320-1323

58. Eskeland R, Leeb M, Grimes GR, Kress C, Boyle S, Sproul D, Gilbert N, Fan Y, Skoultchi Al, Wutz A (2010) Ring1B compacts chromatin structure and represses gene expression independent of histone ubiquitination. Mol Cell 38 (3):452-464

59. Noordermeer D, Leleu M, Splinter E, Rougemont J, De Laat W, Duboule D (2011) The dynamic architecture of Hox gene clusters. Science 334 (6053):222-225

60. de Napoles M, Mermoud JE, Wakao R, Tang YA, Endoh M, Appanah R, Nesterova TB, Silva J, Otte $A P$, Vidal $M(2004)$ Polycomb group proteins Ring1A/B link ubiquitylation of histone $H 2 A$ to heritable gene silencing and $X$ inactivation. Dev Cell 7 (5):663-676

61. Simon JA, Kingston RE (2013) Occupying chromatin: Polycomb mechanisms for getting to genomic targets, stopping transcriptional traffic, and staying put. Mol Cell 49 (5):808-824 
62. Kanhere A, Viiri K, Araújo CC, Rasaiyaah J, Bouwman RD, Whyte WA, Pereira CF, Brookes E, Walker K, Bell GW (2010) Short RNAs are transcribed from repressed polycomb target genes and interact with polycomb repressive complex-2. Mol Cell 38 (5):675-688

63. Rinn JL, Kertesz M, Wang JK, Squazzo SL, Xu X, Brugmann SA, Goodnough LH, Helms JA, Farnham PJ, Segal E (2007) Functional demarcation of active and silent chromatin domains in human HOX loci by noncoding RNAs. Cell 129 (7):1311-1323

64. Zhao J, Sun BK, Erwin JA, Song J-J, Lee JT (2008) Polycomb proteins targeted by a short repeat RNA to the mouse $X$ chromosome. Science 322 (5902):750-756

65. Tsai M-C, Manor O, Wan Y, Mosammaparast N, Wang JK, Lan F, Shi Y, Segal E, Chang HY (2010) Long noncoding RNA as modular scaffold of histone modification complexes. Science 329 (5992):689-693

66. Liu G-Y, Zhao G-N, Chen X-F, Hao D-L, Zhao X, Lv X, Liu D-P (2015) The long noncoding RNA Gm15055 represses Hoxa gene expression by recruiting PRC2 to the gene cluster. Nucleic Acids Res 44 (6):2613-2627

67. Lai K-MV, Gong G, Atanasio A, Rojas J, Quispe J, Posca J, White D, Huang M, Fedorova D, Grant $C$ (2015) Diverse phenotypes and specific transcription patterns in twenty mouse lines with ablated LincRNAs. PLoS One 10 (4):e0125522

68. Sauvageau M, Goff LA, Lodato S, Bonev B, Groff AF, Gerhardinger C, Sanchez-Gomez DB, Hacisuleyman E, Li E, Spence M (2013) Multiple knockout mouse models reveal lincRNAs are required for life and brain development. Elife 2:e01749. doi:10.7554/eLife.01749

69. Amandio AR, Necsulea A, Joye E, Mascrez B, Duboule D (2016) Hotair is dispensible for mouse development. PLoS genetics 12 (12):e1006232

70. Li L, Liu B, Wapinski OL, Tsai M-C, Qu K, Zhang J, Carlson JC, Lin M, Fang F, Gupta RA (2013) Targeted disruption of Hotair leads to homeotic transformation and gene derepression. Cell reports $5(1): 3-12$

71. Schorderet P, Duboule D (2011) Structural and functional differences in the long non-coding RNA hotair in mouse and human. PLoS genetics 7 (5):e1002071

72. Klose RJ, Cooper S, Farcas AM, Blackledge NP, Brockdorff N (2013) Chromatin sampling-an emerging perspective on targeting polycomb repressor proteins. PLoS genetics 9 (8):e1003717

73. Maupetit-Méhouas S, Montibus B, Nury D, Tayama C, Wassef M, Kota SK, Fogli A, Cerqueira Campos F, Hata K, Feil R (2015) Imprinting control regions (ICRs) are marked by mono-allelic bivalent chromatin when transcriptionally inactive. Nucleic Acids Res 44 (2):621-635

74. Riising EM, Comet I, Leblanc B, Wu X, Johansen JV, Helin K (2014) Gene silencing triggers polycomb repressive complex 2 recruitment to CpG islands genome wide. Mol Cell 55 (3):347-360 75. Wang P, Lin C, Smith ER, Guo H, Sanderson BW, Wu M, Gogol M, Alexander T, Seidel C, Wiedemann LM (2009) Global analysis of H3K4 methylation defines MLL family member targets and points to a role for MLL1-mediated H3K4 methylation in the regulation of transcriptional initiation by RNA polymerase II. Mol Cell Biol 29 (22):6074-6085

76. Agger K, Cloos PA, Christensen J, Pasini D, Rose S, Rappsilber J, Issaeva I, Canaani E, Salcini AE, Helin K (2007) UTX and JMJD3 are histone H3K27 demethylases involved in HOX gene regulation and development. Nature 449 (7163):731

77. Lan F, Bayliss PE, Rinn JL, Whetstine JR, Wang JK, Chen S, Iwase S, Alpatov R, Issaeva I, Canaani E (2007) A histone H3 lysine 27 demethylase regulates animal posterior development. Nature 449 (7163):689

78. Lee MG, Villa R, Trojer P, Norman J, Yan K-P, Reinberg D, Di Croce L, Shiekhattar R (2007) Demethylation of H3K27 regulates polycomb recruitment and H2A ubiquitination. Science 318 (5849):447-450 
79. Wang KC, Yang YW, Liu B, Sanyal A, Corces-Zimmerman R, Chen Y, Lajoie BR, Protacio A, Flynn RA, Gupta RA (2011) A long noncoding RNA maintains active chromatin to coordinate homeotic gene expression. Nature 472 (7341):120

80. Ardehali MB, Mei A, Zobeck KL, Caron M, Lis JT, Kusch T (2011) Drosophila Set1 is the major histone $\mathrm{H} 3$ lysine 4 trimethyltransferase with role in transcription. The EMBO journal 30 (14):28172828

81. Denholtz M, Bonora G, Chronis C, Splinter E, de Laat W, Ernst J, Pellegrini M, Plath K (2013) Longrange chromatin contacts in embryonic stem cells reveal a role for pluripotency factors and polycomb proteins in genome organization. Cell stem cell 13 (5):602-616

82. Vieux-Rochas M, Fabre PJ, Leleu M, Duboule D, Noordermeer D (2015) Clustering of mammalian Hox genes with other H3K27me3 targets within an active nuclear domain. Proceedings of the National Academy of Sciences 112 (15):4672-4677

83. Gonzalez-Quevedo R, Lee Y, Poss KD, Wilkinson DG (2010) Neuronal regulation of the spatial patterning of neurogenesis. Dev Cell 18 (1):136-147

84. Guthrie S, Prince V, Lumsden A (1993) Selective dispersal of avian rhombomere cells in orthotopic and heterotopic grafts. Development 118 (2):527-538

85. Wingate R, Lumsden A (1996) Persistence of rhombomeric organisation in the postsegmental hindbrain. Development 122 (7):2143-2152

86. Philippidou P, Dasen JS (2013) Hox genes: choreographers in neural development, architects of circuit organization. Neuron 80 (1):12-34

87. Hunt P, Gulisano M, Cook M, Sham M-H, Faiella A, Wilkinson D, Boncinelli E, Krumlauf R (1991) A distinct Hox code for the branchial region of the vertebrate head. Nature 353 (6347):861

88. Lumsden A, Krumlauf R (1996) Patterning the vertebrate neuraxis. Science 274 (5290):11091115

89. Wilkinson DG, Bhatt S, Cook M, Boncinelli E, Krumlauf R (1989) Segmental expression of Hox-2 homoeobox-containing genes in the developing mouse hindbrain. Nature 341 (6241):405

90. Dasen JS, Liu J-P, Jessell TM (2003) Motor neuron columnar fate imposed by sequential phases of Hox-c activity. Nature 425 (6961):926

91. Ghosh P, Sagerström CG (2018) Developing roles for Hox proteins in hindbrain gene regulatory networks. The International journal of developmental biology 62 (11-12):767-774

92. Jung H, Lacombe J, Mazzoni EO, Liem Jr KF, Grinstein J, Mahony S, Mukhopadhyay D, Gifford DK, Young RA, Anderson KV (2010) Global control of motor neuron topography mediated by the repressive actions of a single hox gene. Neuron 67 (5):781-796

93. Parker HJ, Bronner ME, Krumlauf R (2016) The vertebrate Hox gene regulatory network for hindbrain segmentation: Evolution and diversification: Coupling of a Hox gene regulatory network to hindbrain segmentation is an ancient trait originating at the base of vertebrates. Bioessays 38 (6):526-538

94. Catela C, Shin MM, Lee DH, Liu J-P, Dasen JS (2016) Hox proteins coordinate motor neuron differentiation and connectivity programs through Ret/Gfra genes. Cell reports 14 (8):1901-1915 95. Dasen JS, Tice BC, Brenner-Morton S, Jessell TM (2005) A Hox regulatory network establishes motor neuron pool identity and target-muscle connectivity. Cell 123 (3):477-491

96. Philippidou P, Walsh CM, Aubin J, Jeannotte L, Dasen JS (2012) Sustained Hox5 gene activity is required for respiratory motor neuron development. Nat Neurosci 15 (12):1636

97. del Toro EDn, Borday V, Davenne M, Neun R, Rijli FM, Champagnat J (2001) Generation of a Novel Functional Neuronal Circuit inHoxa1 Mutant Mice. J Neurosci 21 (15):5637-5642

98. Di Bonito M, Narita Y, Avallone B, Sequino L, Mancuso M, Andolfi G, Franzè AM, Puelles L, Rijli FM, Studer M (2013) Assembly of the auditory circuitry by a Hox genetic network in the mouse brainstem. PLoS genetics 9 (2):e1003249 
99. Oury F, Murakami Y, Renaud J-S, Pasqualetti M, Charnay P, Ren S-Y, Rijli FM (2006) Hoxa2-and rhombomere-dependent development of the mouse facial somatosensory map. Science 313 (5792):1408-1413

100. Bel-Vialar S, Itasaki N, Krumlauf R (2002) Initiating Hox gene expression: in the early chick neural tube differential sensitivity to FGF and RA signaling subdivides the HoxB genes in two distinct groups. Development 129 (22):5103-5115

101. Alexander T, Nolte C, Krumlauf R (2009) Hox genes and segmentation of the hindbrain and axial skeleton. Annu Rev Cell Dev Biol 25:431-456

102. Nordström U, Maier E, Jessell TM, Edlund T (2006) An early role for WNT signaling in specifying neural patterns of $\mathrm{Cdx}$ and Hox gene expression and motor neuron subtype identity. PLoS Biol 4 (8):e252

103. Tabaries S, Lapointe J, Besch T, Carter M, Woollard J, Tuggle CK, Jeannotte L (2005) Cdx protein interaction with Hoxa5 regulatory sequences contributes to Hoxa5 regional expression along the axial skeleton. Mol Cell Biol 25 (4):1389-1401

104. Mazzoni EO, Mahony S, Peljto M, Patel T, Thornton SR, McCuine S, Reeder C, Boyer LA, Young RA, Gifford DK (2013) Saltatory remodeling of Hox chromatin in response to rostrocaudal patterning signals. Nat Neurosci 16 (9):1191

105. Gould A, Morrison A, Sproat G, White R, Krumlauf R (1997) Positive cross-regulation and enhancer sharing: two mechanisms for specifying overlapping Hox expression patterns. Genes Dev 11 (7):900-913

106. Manzanares M, Bel-Vialar S, Ariza-McNaughton L, Ferretti E, Marshall H, Maconochie MM, Blasi $F$, Krumlauf R (2001) Independent regulation of initiation and maintenance phases of Hoxa3 expression in the vertebrate hindbrain involve auto-and cross-regulatory mechanisms. Development 128 (18):3595-3607

107. Dasen JS, Jessell TM (2009) Chapter six Hox networks and the origins of motor neuron diversity. Curr Top Dev Biol 88:169-200

108. Krumlauf R (2016) Hox genes and the hindbrain: A study in segments. In: Current topics in developmental biology, vol 116. Elsevier, pp 581-596. doi:10.1016/bs.ctdb.2015.12.011

109. Di Meglio T, Kratochwil CF, Vilain N, Loche A, Vitobello A, Yonehara K, Hrycaj SM, Roska B, Peters AH, Eichmann A (2013) Ezh2 orchestrates topographic migration and connectivity of mouse precerebellar neurons. Science 339 (6116):204-207

110. Golden MG, Dasen JS (2012) Polycomb repressive complex 1 activities determine the columnar organization of motor neurons. Genes Dev 26 (19):2236-2250

111. Holland PW (2013) Evolution of homeobox genes. Wiley Interdisciplinary Reviews: Developmental Biology 2 (1):31-45

112. Salmani BY, Cobeta IM, Rakar J, Bauer S, Curt JR, Starkenberg A, Thor S (2018) Evolutionarily conserved anterior expansion of the central nervous system promoted by a common PcG-Hox program. Development 145 (7). doi:10.1242/dev.160747

113. Bahrampour S, Jonsson C, Thor S (2019) Brain expansion promoted by polycomb-mediated anterior enhancement of a neural stem cell proliferation program. PLoS Biol 17 (2):e3000163

114. Golub TR, Slonim DK, Tamayo P, Huard C, Gaasenbeek M, Mesirov JP, Coller H, Loh ML, Downing $J R$, Caligiuri MA, Bloomfield CD, Lander ES (1999) Molecular classification of cancer: class discovery and class prediction by gene expression monitoring. Science 286 (5439):531-537. doi:10.1126/science.286.5439.531

115. Nakamura T, Largaespada DA, Lee MP, Johnson LA, Ohyashiki K, Toyama K, Chen SJ, Willman CL, Chen IM, Feinberg AP, Jenkins NA, Copeland NG, Shaughnessy JD, Jr. (1996) Fusion of the nucleoporin gene NUP98 to HOXA9 by the chromosome translocation $t(7 ; 11)(p 15 ; p 15)$ in human myeloid leukaemia. Nat Genet 12 (2):154-158. doi:10.1038/ng0296-154 
116. Fujino T, Suzuki A, Ito Y, Ohyashiki K, Hatano Y, Miura I, Nakamura T (2002) Single-translocation and double-chimeric transcripts: detection of NUP98-HOXA9 in myeloid leukemias with HOXA11 or HOXA13 breaks of the chromosomal translocation $t(7 ; 11)(p 15 ; p 15)$. Blood 99 (4):1428-1433 117. Borrow J, Shearman AM, Stanton VP, Jr., Becher R, Collins T, Williams AJ, Dube I, Katz F, Kwong YL, Morris C, Ohyashiki K, Toyama K, Rowley J, Housman DE (1996) The t(7;11)(p15;p15) translocation in acute myeloid leukaemia fuses the genes for nucleoporin NUP98 and class 1 homeoprotein HOXA9. Nat Genet 12 (2):159-167. doi:10.1038/ng0296-159

118. Esposito MT, Zhao L, Fung TK, Rane JK, Wilson A, Martin N, Gil J, Leung AY, Ashworth A, So CW (2015) Synthetic lethal targeting of oncogenic transcription factors in acute leukemia by PARP inhibitors. Nat Med 21 (12):1481-1490. doi:10.1038/nm.3993

119. Cantile M, Pettinato G, Procino A, Feliciello I, Cindolo L, Cillo C (2003) In vivo expression of the whole HOX gene network in human breast cancer. Eur J Cancer 39 (2):257-264

120. Ma XJ, Dahiya S, Richardson E, Erlander M, Sgroi DC (2009) Gene expression profiling of the tumor microenvironment during breast cancer progression. Breast Cancer Res 11 (1):R7. doi:10.1186/bcr2222

121. Unger MA, Lakins J, Zhang HX, Foster W, Baxter BJ, Chodosh L, Weaver VM, Weber BL (2002) HoxA9 is a novel breast cancer progression gene identified by microarray analysis. Am J Hum Genet $71(4): 181-181$

122. Costa BM, Smith JS, Chen Y, Chen J, Phillips HS, Aldape KD, Zardo G, Nigro J, James CD, Fridlyand J, Reis RM, Costello JF (2010) Reversing HOXA9 oncogene activation by PI3K inhibition: epigenetic mechanism and prognostic significance in human glioblastoma. Cancer Res 70 (2):453-462. doi:10.1158/0008-5472.CAN-09-2189

123. Gaspar N, Marshall L, Perryman L, Bax DA, Little SE, Viana-Pereira M, Sharp SY, Vassal G, Pearson AD, Reis RM, Hargrave D, Workman P, Jones C (2010) MGMT-independent temozolomide resistance in pediatric glioblastoma cells associated with a PI3-kinase-mediated HOX/stem cell gene signature. Cancer Res 70 (22):9243-9252. doi:10.1158/0008-5472.CAN-10-1250

124. Murat A, Migliavacca E, Gorlia T, Lambiv WL, Shay T, Hamou MF, de Tribolet N, Regli L, Wick W, Kouwenhoven MC, Hainfellner JA, Heppner FL, Dietrich PY, Zimmer Y, Cairncross JG, Janzer RC, Domany E, Delorenzi M, Stupp R, Hegi ME (2008) Stem cell-related "self-renewal" signature and high epidermal growth factor receptor expression associated with resistance to concomitant chemoradiotherapy in glioblastoma. J Clin Oncol 26 (18):3015-3024. doi:10.1200/JCO.2007.15.7164 125. Abdel-Fattah R, Xiao A, Bomgardner D, Pease CS, Lopes MBS, Hussaini IM (2006) Differential expression of HOX genes in neoplastic and non-neoplastic human astrocytes. J Pathol 209 (1):15-24. doi:10.1002/path.1939

126. Tabuse M, Ohta S, Ohashi Y, Fukaya R, Misawa A, Yoshida K, Kawase T, Saya H, Thirant C, Chneiweiss H, Matsuzaki Y, Okano H, Kawakami Y, Toda M (2011) Functional analysis of HOXD9 in human gliomas and glioma cancer stem cells. Mol Cancer 10 (1):60. doi:10.1186/1476-4598-10-60 127. Bodey B, Bodey B, Jr., Siegel SE, Kaiser HE (2000) Immunocytochemical detection of the homeobox B3, B4, and C6 gene products in childhood medulloblastomas/primitive neuroectodermal tumors. Anticancer Res 20 (3A):1769-1780

128. Tiberio C, Barba P, Magli MC, Arvelo F, Le Chevalier T, Poupon MF, Cillo C (1994) HOX gene expression in human small-cell lung cancers xenografted into nude mice. Int J Cancer 58 (4):608-615 129. Calvo R, West J, Franklin W, Erickson P, Bemis L, Li E, Helfrich B, Bunn P, Roche J, Brambilla E, Rosell R, Gemmill RM, Drabkin HA (2000) Altered HOX and WNT7A expression in human lung cancer. Proc Natl Acad Sci U S A 97 (23):12776-12781. doi:DOI 10.1073/pnas.97.23.12776

130. De Vita G, Barba P, Odartchenko N, Givel JC, Freschi G, Bucciarelli G, Magli MC, Boncinelli E, Cillo C (1993) Expression of homeobox-containing genes in primary and metastatic colorectal cancer. Eur J Cancer 29A (6):887-893 
131. Alami Y, Castronovo V, Belotti D, Flagiello D, Clausse N (1999) HOXC5 and HOXC8 expression are selectively turned on in human cervical cancer cells compared to normal keratinocytes. Biochem Biophys Res Commun 257 (3):738-745. doi:10.1006/bbrc.1999.0516

132. Cantile M, Cindolo L, Napodano G, Altieri V, Cillo C (2003) Hyperexpression of locus C genes in the HOX network is strongly associated in vivo with human bladder transitional cell carcinomas. Oncogene 22 (41):6462-6468. doi:10.1038/sj.onc.1206808

133. Reinert T, Modin C, Castano FM, Lamy P, Wojdacz TK, Hansen LL, Wiuf C, Borre M, Dyrskjot L, Orntoft TF (2011) Comprehensive Genome Methylation Analysis in Bladder Cancer: Identification and Validation of Novel Methylated Genes and Application of These as Urinary Tumor Markers. Clin Cancer Res 17 (17):5582-5592. doi:Doi 10.1158/1078-0432.Ccr-10-2659

134. Cillo C, Barba P, Freschi G, Bucciarelli G, Magli MC, Boncinelli E (1992) HOX gene expression in normal and neoplastic human kidney. Int J Cancer 51 (6):892-897

135. Cancer Today (2016) IARC. http://gco.iarc.fr/today. Accessed 2018

136. Burnet NG, Jefferies SJ, Benson RJ, Hunt DP, Treasure FP (2005) Years of life lost (YLL) from cancer is an important measure of population burden--and should be considered when allocating research funds. Br J Cancer 92 (2):241-245. doi:10.1038/sj.bjc.6602321

137. Walsh KM, Ohgaki H, Wrensch MR (2016) Epidemiology. Handb Clin Neurol 134:3-18. doi:10.1016/B978-0-12-802997-8.00001-3

138. Ostrom QT, Gittleman H, Liao P, Vecchione-Koval T, Wolinsky Y, Kruchko C, Barnholtz-Sloan JS (2017) CBTRUS Statistical Report: Primary brain and other central nervous system tumors diagnosed in the United States in 2010-2014. Neuro Oncol 19 (suppl_5):v1-v88. doi:10.1093/neuonc/nox158 139. Louis DN, Ohgaki H, Wiestler OD, Cavenee WK, Burger PC, Jouvet A, Scheithauer BW, Kleihues P (2007) The 2007 WHO classification of tumours of the central nervous system. Acta Neuropathol 114 (2):97-109. doi:10.1007/s00401-007-0243-4

140. Chen R, Smith-Cohn M, Cohen AL, Colman H (2017) Glioma Subclassifications and Their Clinical Significance. Neurotherapeutics 14 (2):284-297. doi:10.1007/s13311-017-0519-x

141. Perry A, Wesseling P (2016) Histologic classification of gliomas. Handb Clin Neurol 134:71-95. doi:10.1016/B978-0-12-802997-8.00005-0

142. Louis DN, Perry A, Reifenberger G, von Deimling A, Figarella-Branger D, Cavenee WK, Ohgaki H, Wiestler OD, Kleihues P, Ellison DW (2016) The 2016 world health organization classification of tumors of the central nervous system: a summary. Acta Neuropathol 131 (6):803-820. doi:10.1007/s00401-016-1545-1

143. Masui K, Mischel PS, Reifenberger G (2016) Molecular classification of gliomas. Handb Clin Neurol 134:97-120. doi:10.1016/B978-0-12-802997-8.00006-2

144. Buccoliero AM, Castiglione F, Degl'Innocenti DR, Ammanati F, Giordano F, Sanzo M, Mussa F, Genitori L, Taddei GL (2009) Hox-D genes expression in pediatric low-grade gliomas: real-time-PCR study. Cell Mol Neurobiol 29 (1):1-6

145. Sun L, Yan W, Wang Y, Sun G, Luo H, Zhang J, Wang X, You Y, Yang Z, Liu N (2011) MicroRNA$10 \mathrm{~b}$ induces glioma cell invasion by modulating MMP-14 and UPAR expression via HOXD10. Brain Res 1389:9-18

146. Duan R, Han L, Wang Q, Wei J, Chen L, Zhang J, Kang C, Wang L (2015) HOXA13 is a potential GBM diagnostic marker and promotes glioma invasion by activating the Wnt and TGF- $\beta$ pathways. Oncotarget 6 (29): 27778

147. Se Y-B, Kim SH, Kim JY, Kim JE, Dho Y-S, Kim JW, Kim YH, Woo HG, Kim S-H, Kang S-H (2017) Underexpression of HOXA11 is associated with treatment resistance and poor prognosis in glioblastoma. Cancer research and treatment: official journal of Korean Cancer Association 49 (2):387-398. doi:10.4143/crt.2016.106 
148. Li Q, Dong C, Cui J, Wang Y, Hong X (2018) Over-expressed IncRNA HOTAIRM1 promotes tumor growth and invasion through up-regulating HOXA1 and sequestering G9a/EZH2/Dnmts away from the HOXA1 gene in glioblastoma multiforme. J Exp Clin Cancer Res 37 (1):265

149. Cimino PJ, Kim Y, Wu H-J, Alexander J, Wirsching H-G, Szulzewsky F, Pitter K, Ozawa T, Wang J, Vazquez J (2018) Increased HOXA5 expression provides a selective advantage for gain of whole chromosome 7 in IDH wild-type glioblastoma. Genes Dev 32 (7-8):512-523

150. Pojo M, Goncalves CS, Xavier-Magalhaes A, Oliveira Al, Goncalves T, Correia S, Rodrigues AJ, Costa S, Pinto L, Pinto AA, Lopes JM, Reis RM, Rocha M, Sousa N, Costa BM (2015) A transcriptomic signature mediated by HOXA9 promotes human glioblastoma initiation, aggressiveness and resistance to temozolomide. Oncotarget 6 (10):7657-7674. doi:10.18632/oncotarget.3150

151. Xu K, Qiu C, Pei H, Mehmood MA, Wang H, Li L, Xia Q (2018) Homeobox B3 promotes tumor cell proliferation and invasion in glioblastoma. Oncol Lett 15 (3):3712-3718

152. Duan X, Liu D, Wang Y, Chen Z (2018) Circular RNA hsa_circ_0074362 promotes glioma cell proliferation, migration, and invasion by attenuating the inhibition of mir-1236-3p on HOXB7 expression. DNA Cell Biol 37 (11):917-924

153. Fang L, Xu Y, Zou L (2014) Overexpressed homeobox B9 regulates oncogenic activities by transforming growth factor- $\beta 1$ in gliomas. Biochem Biophys Res Commun 446 (1):272-279

154. Yan T-f, Wu M-j, Xiao B, Hu Q, Fan Y-H, Zhu X-G (2018) Knockdown of HOXC6 inhibits glioma cell proliferation and induces cell cycle arrest by targeting WIF-1 in vitro and vivo. PathologyResearch and Practice 214 (11):1818-1824

155. Okamoto OK, Oba-Shinjo SM, Lopes L, Marie SKN (2007) Expression of HOXC9 and E2F2 are upregulated in $\mathrm{CD} 133(+)$ cells isolated from human astrocytomas and associate with transformation of human astrocytes. Biochim Biophys Acta 1769 (7-8):437-442. doi:10.1016/j.bbaexp.2007.05.002

156. Li S, Zhang W, Wu C, Gao H, Yu J, Wang X, Li B, Jun Z, Zhang W, Zhou P (2018) HOXC 10 promotes proliferation and invasion and induces immunosuppressive gene expression in glioma. The FEBS journal 285 (12):2278-2291

157. Guan Y, He Y, Lv S, Hou X, Li L, Song J (2019) Overexpression of HOXC10 promotes glioblastoma cell progression to a poor prognosis via the PI3K/AKT signalling pathway. J Drug Target 27 (1):60-66 158. Zhao X-W, Zhan Y-B, Bao J-J, Zhou J-Q, Zhang F-J, Bin Y, Bai Y-H, Wang Y-M, Zhang Z-Y, Liu X-Z (2017) Clinicopathological analysis of HOXD4 expression in diffuse gliomas and its correlation with IDH mutations and 1p/19q co-deletion. Oncotarget 8 (70):115657

159. Han L, Liu D, Li Z, Tian N, Han Z, Wang G, Fu Y, Guo Z, Zhu Z, Du C (2015) HOXB1 is a tumor suppressor gene regulated by miR-3175 in glioma. PLoS One 10 (11):e0142387

160. Hu X, Chen D, Cui Y, Li Z, Huang J (2013) Targeting microRNA-23a to inhibit glioma cell invasion via HOXD10. Sci Rep 3:3423

161. Gallo M, Ho J, Coutinho FJ, Vanner R, Lee L, Head R, Ling EK, Clarke ID, Dirks PB (2013) A tumorigenic MLL-homeobox network in human glioblastoma stem cells. Cancer Res 73 (1):417-427 162. Li B, McCrudden CM, Yuen HF, Xi X, Lyu P, Chan KW, Zhang SD, Kwok HF (2017) CD133 in brain tumor: the prognostic factor. Oncotarget 8 (7):11144

163. The Cancer Genome Atlas Research Network (2008) Comprehensive genomic characterization defines human glioblastoma genes and core pathways. Nature 455 (7216):1061-1068. doi:10.1038/nature07385

164. The Cancer Genome Atlas Research Network (2015) Comprehensive, Integrative Genomic Analysis of Diffuse Lower-Grade Gliomas. N Engl J Med 372 (26):2481-2498. doi:10.1056/NEJMoa1402121

165. Xuan F, Huang M, Liu W, Ding H, Yang L, Cui H (2015) Homeobox C9 suppresses Beclin1mediated autophagy in glioblastoma by directly inhibiting the transcription of death-associated protein kinase 1. Neuro Oncol 18 (6):819-829 
166. Chen B, Liang T, Yang P, Wang H, Liu Y, Yang F, You G (2016) Classifying lower grade glioma cases according to whole genome gene expression. Oncotarget 7 (45):74031

167. Guo YB, Shao YM, Chen J, Xu SB, Zhang XD, Wang MR, Liu HY (2016) Effect of overexpression of HOX genes on its invasive tendency in cerebral glioma. Oncol Lett 11 (1):75-80

168. Tan Z, Chen K, Wu W, Zhou Y, Zhu J, Wu G, Cao L, Zhang X, Guan H, Yang Y (2018) Overexpression of HOXC10 promotes angiogenesis in human glioma via interaction with PRMT5 and upregulation of VEGFA expression. Theranostics 8 (18):5143

169. Kim JW, Kim JY, Kim JE, Kim S-K, Chung H-T, Park C-K (2014) HOXA10 is associated with temozolomide resistance through regulation of the homologous recombinant DNA repair pathway in glioblastoma cell lines. Genes Cancer 5 (5-6):165

170. Lin J, Teo S, Lam DH, Jeyaseelan K, Wang S (2012) MicroRNA-10b pleiotropically regulates invasion, angiogenicity and apoptosis of tumor cells resembling mesenchymal subtype of glioblastoma multiforme. Cell Death Dis 3 (10):e398

171. Yachi K, Tsuda M, Kohsaka S, Wang L, Oda Y, Tanikawa S, Ohba Y, Tanaka S (2018) miR-23a promotes invasion of glioblastoma via HOXD10-regulated glial-mesenchymal transition. Signal transduction and targeted therapy 3 (1):33

172. Court F, Le Boiteux E, Fogli A, Müller-Barthélémy $M$, Vaurs-Barriére $C$, Chautard E, Pereira B, Biau J, Kemeny J-L, Khalil T, Karayan-Tapon L, Verelle P, Arnaud P (2019) Transcriptional alterations in glioma result primarily from DNA methylation-independent mechanisms. Genome Res 29 (10):1605-1621. doi:10.1101/gr.249219.119

173. Dong CG, Wu WK, Feng SY, Wang XJ, Shao JF, Qiao J (2012) Co-inhibition of microRNA-10b and microRNA-21 exerts synergistic inhibition on the proliferation and invasion of human glioma cells. Int J Oncol 41 (3):1005-1012

174. Martinez R, Martin-Subero JI, Rohde V, Kirsch M, Alaminos M, Fernandez AF, Ropero S, Schackert G, Esteller M (2009) A microarray-based DNA methylation study of glioblastoma multiforme. Epigenetics 4 (4):255-264

175. Kurscheid S, Bady P, Sciuscio D, Samarzija I, Shay T, Vassallo I, Criekinge WV, Daniel RT, van den Bent MJ, Marosi C (2015) Chromosome 7 gain and DNA hypermethylation at the HOXA10 locus are associated with expression of a stem cell related HOX-signature in glioblastoma. Genome Biol 16 (1):16

176. Court F, Arnaud P (2017) An annotated list of bivalent chromatin regions in human ES cells: a new tool for cancer epigenetic research. Oncotarget 8 (3):4110

177. Di Vinci A, Casciano I, Marasco E, Banelli B, Ravetti GL, Borzì L, Brigati C, Forlani A, Dorcaratto A, Allemanni G (2012) Quantitative methylation analysis of HOXA3, 7, 9, and 10 genes in glioma: association with tumor WHO grade and clinical outcome. J Cancer Res Clin Oncol 138 (1):35-47

178. Flavahan WA, Drier Y, Liau BB, Gillespie SM, Venteicher AS, Stemmer-Rachamimov AO, Suvà ML, Bernstein BE (2016) Insulator dysfunction and oncogene activation in IDH mutant gliomas. Nature 529 (7584):110

179. Brinkman AB, Gu H, Bartels SJ, Zhang Y, Matarese F, Simmer F, Marks H, Bock C, Gnirke A, Meissner A (2012) Sequential ChIP-bisulfite sequencing enables direct genome-scale investigation of chromatin and DNA methylation cross-talk. Genome Res 22 (6):1128-1138

180. Reddington JP, Perricone SM, Nestor CE, Reichmann J, Youngson NA, Suzuki M, Reinhardt D, Dunican DS, Prendergast JG, Mjoseng H (2013) Redistribution of H3K27me3 upon DNA hypomethylation results in de-repression of Polycomb target genes. Genome Biol 14 (3):R25 182. Goncalves CS, Xavier-Magalhaes A, Pojo M, Oliveira Al, Correia S, Reis RM, Sousa N, Rocha M, Costa BM (2015) Transcriptional profiling of HOXA9-regulated genes in human glioblastoma cell models. Genom Data 5:54-58. doi:10.1016/j.gdata.2015.05.010 
183. Xavier-Magalhães A, Gonçalves CS, Fogli A, Lourenço T, Pojo M, Pereira B, Rocha M, Lopes MC, Crespo I, Rebelo O (2018) The long non-coding RNA HOTAIR is transcriptionally activated by HOXA9 and is an independent prognostic marker in patients with malignant glioma. Oncotarget 9 (21):15740-15756. doi:10.18632/oncotarget.24597

184. Gonçalves CS, Xavier-Magalhães A, Martins EP, Pinto AA, Pires MM, Pinheiro C, Reis RM, Sousa N, Costa BM (2020) A novel molecular link between HOXA9 and WNT6 in glioblastoma identifies a subgroup of patients with particular poor prognosis. Mol Oncol. doi:10.1002/1878-0261.12633 185. Gonçalves CS, Vieira de Castro J, Pojo M, Martins EP, Queirós S, Chautard E, Taipa R, Pires MM, Pinto AA, Pardal F, Custódia C, Faria CC, Clara C, Reis RM, Sousa N, Costa BM (2018) WNT6 is a Novel Oncogenic Prognostic Biomarker in Human Glioblastoma. Theranostics 8 (17):4805-4823. doi:10.7150/thno.25025

186. Herrlinger U, Schäfer N, Steinbach JP, Weyerbrock A, Hau P, Goldbrunner R, Friedrich F, Rohde V, Ringel F, Schlegel U (2016) Bevacizumab Plus Irinotecan Versus Temozolomide in Newly Diagnosed O6-Methylguanine-DNA Methyltransferase Nonmethylated Glioblastoma: The Randomized GLARIUS Trial. J Clin Oncol 34 (14):1611-1619

187. Chinot OL, Wick W, Mason W, Henriksson R, Saran F, Nishikawa R, Carpentier AF, Hoang-Xuan K, Kavan P, Cernea D (2014) Bevacizumab plus radiotherapy-temozolomide for newly diagnosed glioblastoma. N Engl J Med 370 (8):709-722

188. Sánchez-Higueras C, Rastogi C, Voutev R, Bussemaker HJ, Mann RS, Hombría JCG (2019) In vivo Hox binding specificity revealed by systematic changes to a single cis regulatory module. Nature communications 10 (1):3597-3597. doi:10.1038/s41467-019-11416-1

189. Mann RS, Affolter M (1998) Hox proteins meet more partners. Curr Opin Genet Dev 8 (4):423429. doi:10.1016/s0959-437x(98)80113-5

190. Dard A, Jia Y, Reboulet J, Bleicher F, Lavau C, Merabet S (2019) The human HOXA9 protein uses paralog-specific residues of the homeodomain to interact with TALE-class cofactors. Sci Rep 9 (1):5664-5664. doi:10.1038/s41598-019-42096-y

191. Porcelli D, Fischer B, Russell S, White R (2019) Chromatin accessibility plays a key role in selective targeting of Hox proteins. Genome Biol 20 (1):115-115. doi:10.1186/s13059-019-1721-4 192. Shinawi T, Hill VK, Krex D, Schackert G, Gentle D, Morris MR, Wei W, Cruickshank G, Maher ER, Latif $F$ (2013) DNA methylation profiles of long-and short-term glioblastoma survivors. Epigenetics $8(2): 149-156$

193. Khan AA, Ham S-J, Yen LN, Lee HL, Huh J, Jeon H, Kim MH, Roh T-Y (2018) A novel role of metal response element binding transcription factor 2 at the Hox gene cluster in the regulation of H3K27me3 by polycomb repressive complex 2. Oncotarget 9 (41):26572-26585. doi:10.18632/oncotarget.25505

194. Li Y, Ren Y, Wang Y, Tan Y, Wang Q, Cai J, Zhou J, Yang C, Zhao K, Yi K, Jin W, Wang L, Liu M, Yang J, Li M, Kang C (2019) A Compound AC1Q3QWB Selectively Disrupts HOTAIR-Mediated Recruitment of PRC2 and Enhances Cancer Therapy of DZNep. Theranostics 9 (16):4608-4623. doi:10.7150/thno.35188

195. Miranda TB, Cortez CC, Yoo CB, Liang G, Abe M, Kelly TK, Marquez VE, Jones PA (2009) DZNep is a global histone methylation inhibitor that reactivates developmental genes not silenced by DNA methylation. Mol Cancer Ther 8 (6):1579-1588. doi:10.1158/1535-7163.MCT-09-0013

196. Ko SY, Ladanyi A, Lengyel E, Naora H (2014) Expression of the homeobox gene HOXA9 in ovarian cancer induces peritoneal macrophages to acquire an M2 tumor-promoting phenotype. Am J Pathol 184 (1):271-281. doi:10.1016/j.ajpath.2013.09.017 
Pirrotta V, Li HB (2012) A view of nuclear Polycomb bodies. Curr Opin Genet Dev. 22(2):101-9. doi: 10.1016/j.gde.2011.11.004.

Casaca A, Hauswirth GM, Bildsoe H, Mallo M, McGlinn E (2018) Regulatory landscape of the Hox transcriptome. Int J Dev Biol. 62(11-12):693-704. doi:10.1387/ijdb.180270em.

Bartel DP.(2018) Metazoan MicroRNAs. Cell. 173(1):20-51. doi:10.1016/j.cell.2018.03.006.

Yekta S, Tabin CJ, Bartel D (2008) MicroRNAs in the Hox network: an apparent link to posterior prevalence. Nat Rev Genet.9(10):789-96. doi: 10.1038/nrg2400.

Mansfield JH, McGlinn E(2012) Evolution, expression, and developmental function of Hoxembedded miRNAs. Curr Top Dev Biol. 99:31-57. doi:10.1016/B978-0-12-387038-4.00002-1.

Hornstein E, Mansfield JH, Yekta S, Hu JK, Harfe BD, McManus MT, Baskerville S, Bartel DP, Tabin CJ.(2005) The microRNA miR-196 acts upstream of Hoxb8 and Shh in limb development. Nature. 438(7068):671-4. PubMed PMID: 16319892.

Asli NS, Kessel M.(2010) Spatiotemporally restricted regulation of generic motor neuron programs by miR-196-mediated repression of Hoxb8. Dev Biol. 344(2):857-68. doi: 10.1016/j.ydbio.2010.06.003.

Gofflot F, Lizen B.(2018) Emerging roles for HOX proteins in synaptogenesis. Int J Dev Biol. 62(1112):807-818. doi: 10.1387/ijdb.180299fg.

Hutlet B, Theys N, Coste C, Ahn MT, Doshishti-Agolli K, Lizen B, Gofflot F.(2016) Systematic expression analysis of Hox genes at adulthood reveals novel patterns in the central nervous system. Brain Struct Funct. 221(3):1223-43. doi: 10.1007/s00429-014-0965-8.

Ohm JE, McGarvey KM, Yu X, Cheng L, Schuebel KE, Cope L, Mohammad HP, Chen W, Daniel VC, Yu W, Berman DM, Jenuwein T, Pruitt K, Sharkis SJ, Watkins DN, Herman JG, Baylin SB (2007)A stem cell-like chromatin pattern may predispose tumor suppressor genes to DNA hypermethylation and heritable silencing. Nat Genet.39(2):237-42.

Deneberg S, Guardiola P, Lennartsson A, Qu Y, Gaidzik V, Blanchet O, Karimi M, Bengtzén S, Nahi H, Uggla B, Tidefelt U, Höglund M, Paul C, Ekwall K, Döhner K, Lehmann S(2011) Prognostic DNA methylation patterns in cytogenetically normal acute myeloid leukemia are predefined by stem cell chromatin marks. Blood. 118(20):5573-82. doi: 10.1182/blood-2011-01-332353.

Johnston MJ, Nikolic A, Ninkovic N, Guilhamon P, Cavalli FMG, Seaman S, Zemp FJ, Lee J, Abdelkareem A, Ellestad K, Murison A, Kushida MM, Coutinho FJ, Ma Y, Mungall AJ, Moore R, Marra MA, Taylor MD, Dirks PB, Pugh TJ, Morrissy S, St Croix B, Mahoney DJ, Lupien M, Gallo M.(2019) High-resolution structural genomics reveals new therapeutic vulnerabilities in glioblastoma. Genome Res. 29(8):1211-1222. doi: 10.1101/gr.246520.118. 


\section{Figure legends}

Fig. 1

\section{HOX expression patterns in the hindbrain and spinal cord}

(a) HOX genes are composed by only two exons and one intron. The homeobox sequence, which encodes a 61-amino-acid peptide motif (the homeodomain) with a distinctive helix-loop-helix-turnhelix structure, is within the second exon. (b) A colour code indicates the relative area of expression of each HOX gene along the anterior-posterior axis in the developing CNS. The left panel illustrate the rhombomere (r)-specific nested patterns of expression of the Hox1-Hox 5 paralogues in the hindbrain. Higher colour intensity indicates higher expression. Positions of motor neuron pools are shown within their rhombomere(s) of origin (Trigem.: Trigeminal; Gl.: Glossopharyngeal). In the spinal cord (right panel), the overlapping Hox4-Hox11 gene expression pattern is shown in relation with the motor neuron columnar organization. MMC: Medial motor column; PMC: Phrenic motor column; LMC: Lateral motor column; PGC: preganglionic motor column; HMC: hypaxial motor column.

\section{Fig. 2}

Topological architecture at the HOXD cluster. The HOXD cluster is localized at the boundary of two adjacent topological associated domains (TAD) that each includes an enhancer-enriched genedesert area. Consequently, the 3' and 5' HOXD genes are controlled by distinct sets of remote enhancers during development. Cen., centromere; Tel., telomere.

\section{Fig. 3}

\section{H3K27me3- and H3K4me3-marked domains demarcate silent and expressed HOX genes}

Encode-derived ChIP-seq and RNA-seq data show H3K27me3 and H3K4me3 distribution and Hoxa gene expression in mouse A) ES cells, B) embryonic kidney and C) forebrain. In ES cells and forebrain, where all Hoxa genes are repressed, H3K27me3 covered the whole cluster. It may be associated with $\mathrm{H} 3 \mathrm{~K} 4 \mathrm{me} 3$ at promoter regions, constituting bivalent domains. In embryonic kidney, two H3K4me3- and H3K27me3-marked domains delineate expressed and repressed genes along the cluster. 
$1 \quad$ Fig. 4

2 Summary of the main functional roles of HOX genes in glioblastoma and their clinical 3 prognostic value.

4 HOX genes display various critical functional roles in GBM (regulation of cell viability, invasion,

5 migration, apoptosis, cell cycle, colony formation, angiogenesis, resistance to temozolomide and to

6 radiotherapy, and stem cell capacity) that are globally associated with malignancy in vitro and in vivo.

7 Importantly, some HOX genes have prognostic value in GBM, with putative clinical relevance. Red

8 and blue colours in the heatmap indicate increased and decreased effects, respectively, upon

9 expression of the corresponding HOX gene. Grey colour indicates unknown effects. Empty cells

10 represent absence of the respective paralogue in that cluster. OS, overall survival; TMZ, 11 temozolomide. 
Figure 1

a

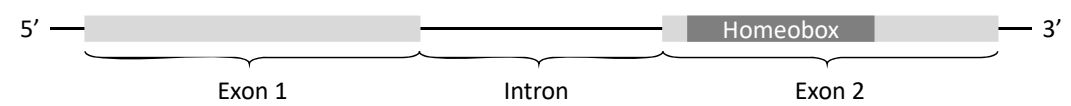

b
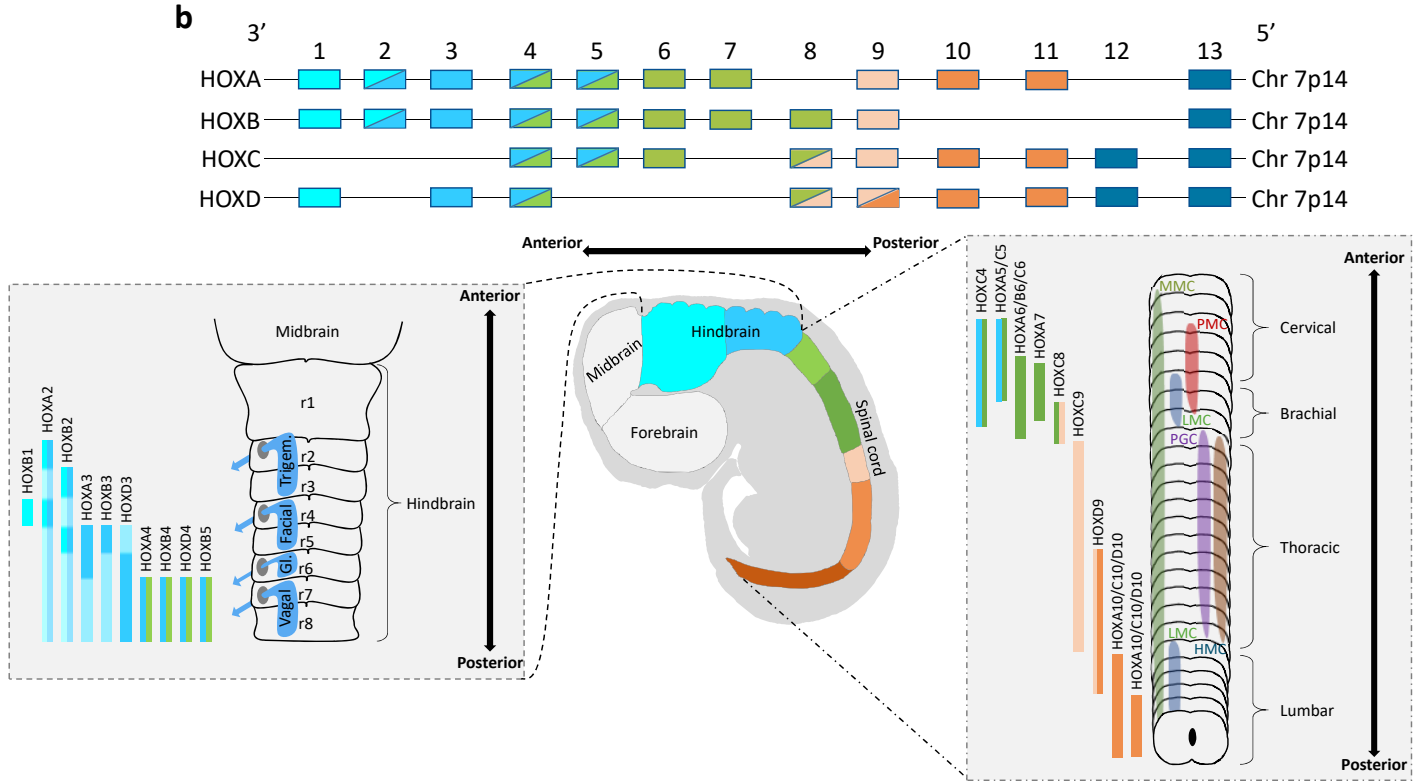
Figure 2

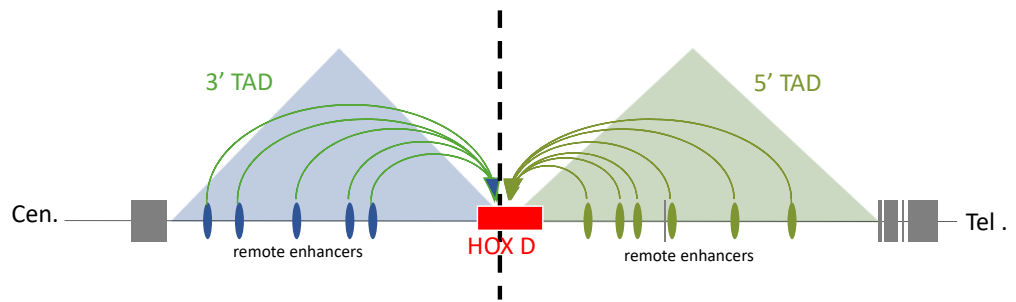


Figure 3

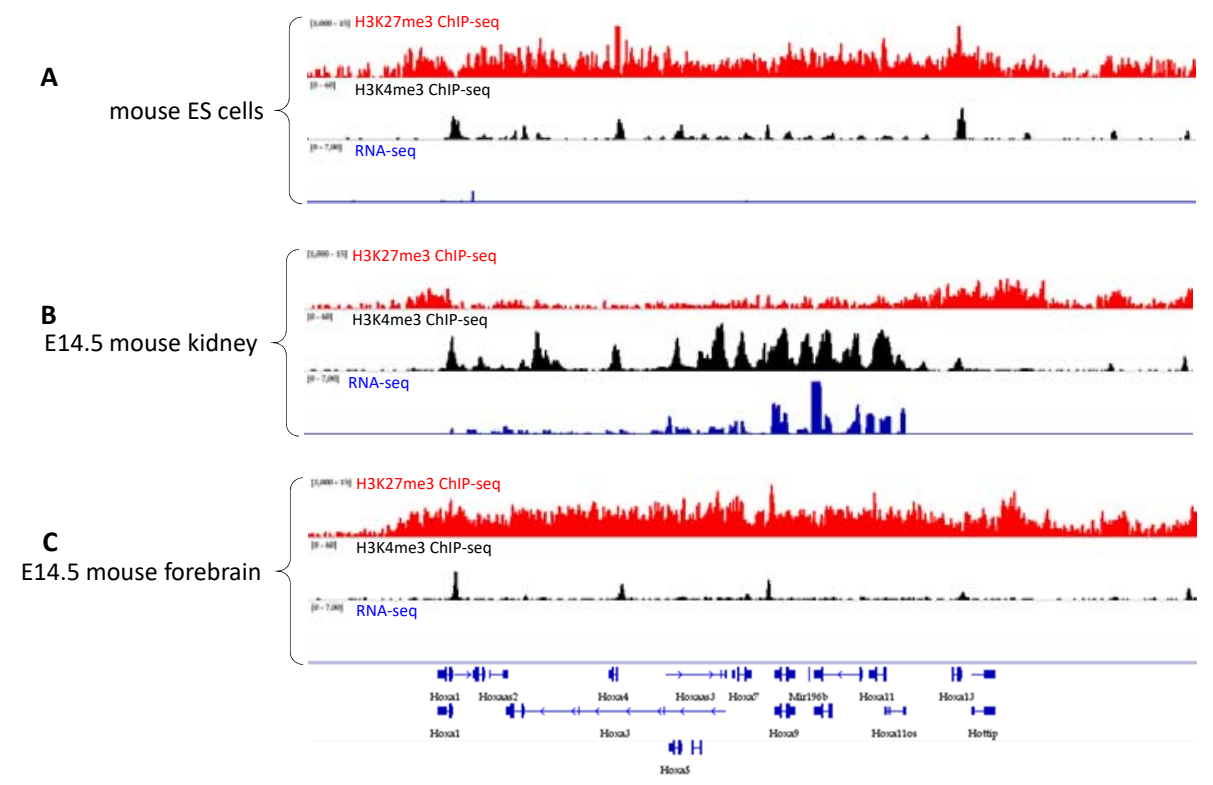




\section{Figure 4}
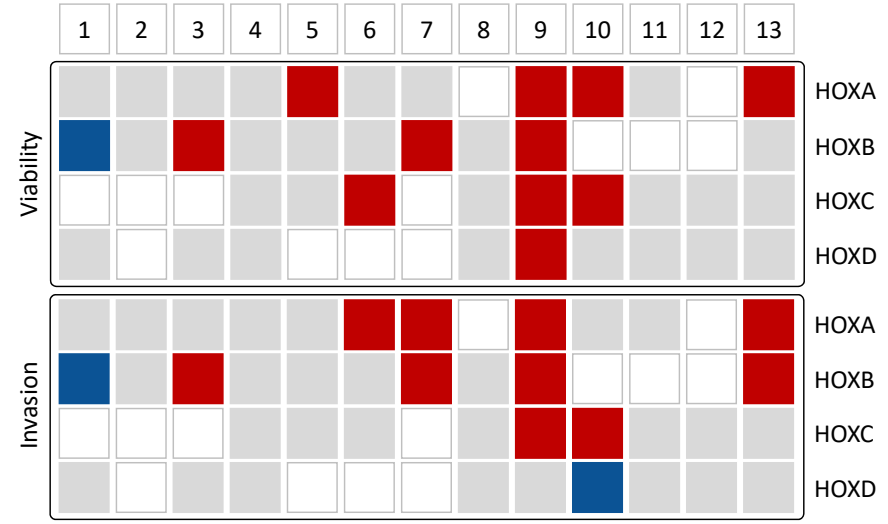

HOXA
HOXB
HOXC

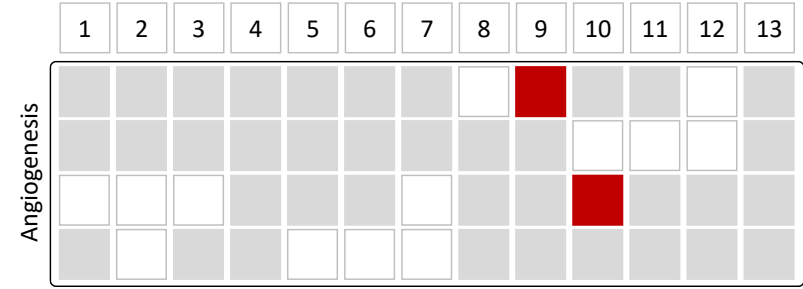

HOXA

HOXB

HOXC

HOXD

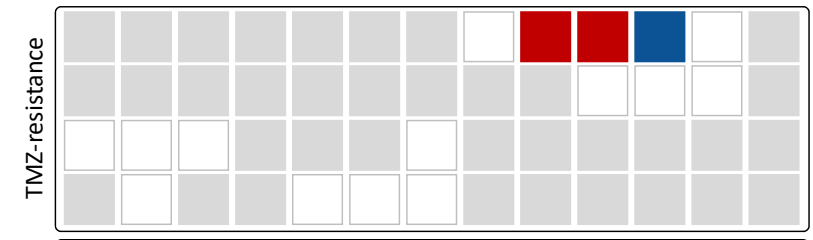

HOXA

HOXB

HOXC

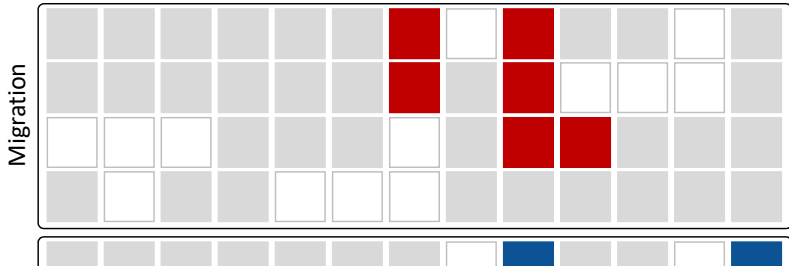

HOXA
HOXB
HOXC
HOXD

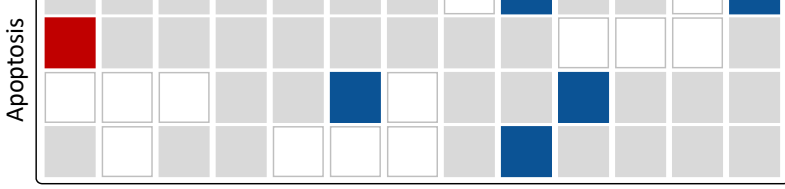

HOXA
HOXB
HOXC
HOXD

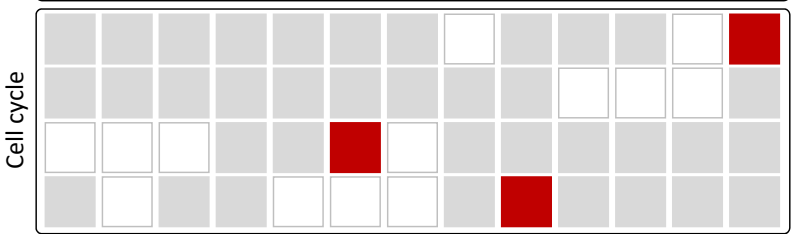

HOXA

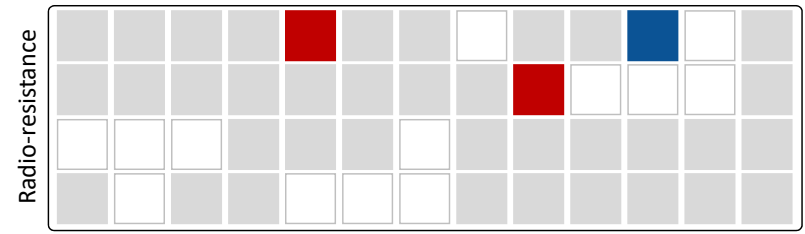

HOXD

HOXA

HOXB

HOXC

HOXD

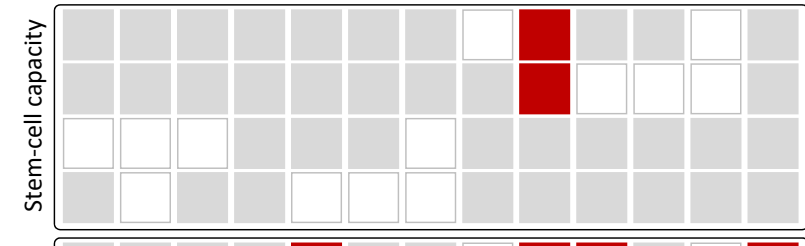

HOXA

HOXB

HOXC HOXD

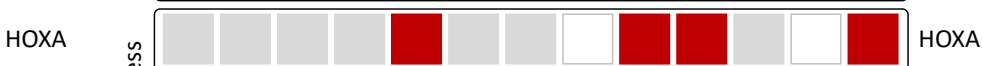

HOXB HOXC HOXD

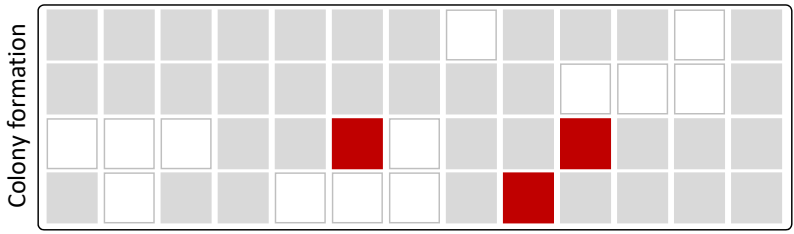
HOXA
HOXB
HOXC
HOXD

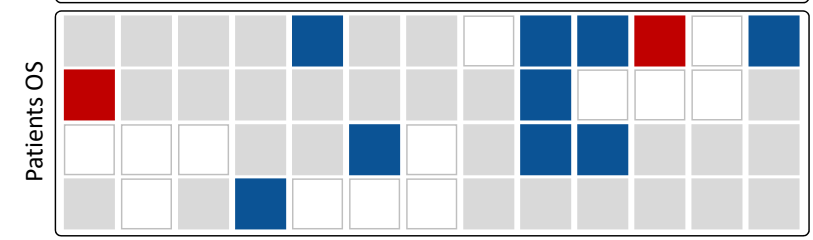

HOXA

HOXB

HOXC

HOXD HOXA HOXB HOXC HOXD 